Article

\title{
Quantitative Structure-Activity Relationships for Structurally Diverse Chemotypes Having Anti-Trypanosoma cruzi Activity
}

\author{
Anacleto S. de Souza ${ }^{1}$, Leonardo L. G. Ferreira ${ }^{1}$, Aldo S. de Oliveira ${ }^{1,2}{ }^{\mathbb{D}}$ and \\ Adriano D. Andricopulo ${ }^{1, *}$ \\ 1 Laboratory of Computational and Medicinal Chemistry, Center for Research and Innovation in Biodiversity \\ and Drug Discovery, Physics Institute of Sao Carlos, University of Sao Paulo, Sao Carlos-SP 13563-120, Brazil; \\ anacletosilvadesouza@usp.br (A.S.d.S.); leonardo@ifsc.usp.br (L.L.G.F.); aldo.sena@ufsc.br (A.S.d.O.) \\ 2 Department of Exact Sciences and Education, Blumenal Center, Federal University of Santa Catarina, \\ Blumenau 89036-256, Brazil \\ * Correspondence: aandrico@ifsc.usp.br; Tel.: +55-16-3373-9874
}

Received: 11 March 2019; Accepted: 17 May 2019; Published: 8 June 2019

\begin{abstract}
Small-molecule compounds that have promising activity against macromolecular targets from Trypanosoma cruzi occasionally fail when tested in whole-cell phenotypic assays. This outcome can be attributed to many factors, including inadequate physicochemical and pharmacokinetic properties. Unsuitable physicochemical profiles usually result in molecules with a poor ability to cross cell membranes. Quantitative structure-activity relationship (QSAR) analysis is a valuable approach to the investigation of how physicochemical characteristics affect biological activity. In this study, artificial neural networks (ANNs) and kernel-based partial least squares regression (KPLS) were developed using anti-T. cruzi activity data for broadly diverse chemotypes. The models exhibited a good predictive ability for the test set compounds, yielding $q^{2}$ values of 0.81 and 0.84 for the ANN and KPLS models, respectively. The results of this investigation highlighted privileged molecular scaffolds and the optimum physicochemical space associated with high anti-T. cruzi activity, which provided important guidelines for the design of novel trypanocidal agents having drug-like properties.
\end{abstract}

Keywords: artificial neural networks; machine learning; Chagas' disease; QSAR; molecular modeling

\section{Introduction}

Chagas' disease, which is a neglected tropical disease (as defined by the World Health Organization, WHO) caused by the protozoan Trypanosoma cruzi, is the leading cause of heart failure in Latin America, where it is endemic [1]. According to the WHO, the disease affects 8 million people worldwide and causes 10,000 deaths every year. Moreover, more than 25 million people live in vulnerable areas under the risk of infection [2]. Current chemotherapy for Chagas' disease is limited to nifurtimox and benznidazole, which are two obsolete drugs identified in 1965 and 1971, respectively (Figure 1). These nitroheterocyclic compounds cause several adverse effects, such as weight loss, neurological damage, anorexia, dermatitis, depression, nausea, and gastrointestinal problems [3,4]. Furthermore, they lack effectiveness in the chronic phase of the disease. Given these drawbacks, novel, effective, and safe drugs for Chagas' disease are urgently needed [5]. 


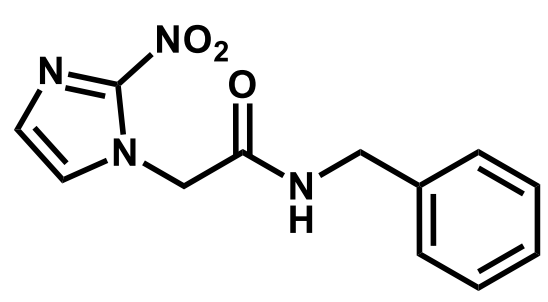

Benznidazole (1)

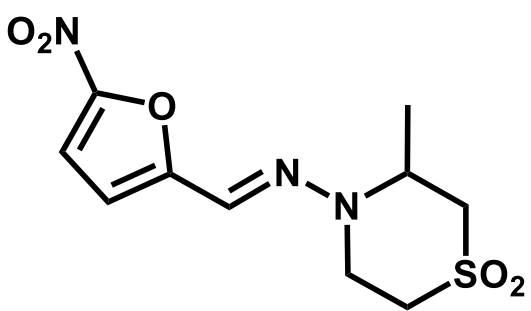

Nifurtimox (2)

Figure 1. Structures of benznidazole and nifurtimox, which are the only two available drugs for the chemotherapy of Chagas' disease.

T. cruzi parasites interconvert into different morphological phases during their life cycle as they circulate between the insect host (the Triatomine bugs Triatoma infestans, Rhodnius prolixus, and Triatoma dimidiata) and the human host. Replicative epimastigotes and infective metacyclic trypomastigotes develop in Triatomine bugs, whereas replicative intracellular amastigotes and non-replicative bloodstream trypomastigotes develop in humans [6]. Intracellular amastigotes, which are found in tissues such as cardiac muscles and the digestive system, are the clinically relevant form of the parasite, and thus are the targets of antichagasic agents [6,7]. Occasionally, compounds that are active against isolated macromolecular targets lose their activity when tested in whole-cell phenotypic assays [8-11]. This activity loss can stem from inappropriate physicochemical properties, which play a key role in the ability of compounds to permeate biological membranes and reach their molecular targets $[12,13]$. In this context, drug discovery players have unprecedentedly relied on chemoinformatics to better understand the relationships between structure, physicochemical properties, and biological activity [14-16]. Quantitative structure-activity relationships (QSAR) have played a major role in this field [17-19]. In this study, we developed artificial neural networks (ANNs) and kernel-based partial least squares models (KPLS) aimed at investigating the molecular events underlying the activity of structurally diverse trypanocidal agents [20,21]. The outcome of these models was used to generate a focused fragment collection and physicochemical heat maps, which provide insights into privileged chemotypes and optimum physicochemical property spaces associated with enhanced trypanocidal activity.

ANNs are aimed to mimic biological neural networks and their processing units, the neurons, are composed of dendrites, a cell body, and axons. All input values (the dendrites) are summed and then are assigned to a learning function (the cell body). The input values are the independent variables and the output values are the dependent variables. The signal (axon) can be propagated or inhibited if the value returned by the activation function is above or below a predetermined threshold, respectively [22]. The multi-layer back-propagation algorithm was used in the ANN models. In particular, the back-propagation method uses the forward and backward steps [23]. First, weights are determined, and the biological activity value is predicted for a compound. The error between experimental and predicted values provides support for adjusting the input weight in the first intermediate layer. The main limitation of the algorithm is the convergence of the network due to low and high values in the learning rate. To reduce this limitation, the term momentum ensures that the learning rate is stabilized.

The fingerprint descriptors in the KPLS models are calculated from the smiles representation of each structure in the dataset [24]. These descriptors can be classified as linear, dendritic, radial, and molprint2D [25]. These four descriptors allow the visualization of atomic contribution maps, which depict the contribution of each atom to the dependent variable. The linear fingerprint descriptor uses the information from the linear fragments and ring closure to convert the structures into binary sequences. The dendritic fingerprint includes branched parts of the molecule during the generation of the binary sequence. Also referred to as extended connectivity fingerprints, the radial fingerprint identifies all heavy atoms and encodes the compounds by assigning fragments that emerge radially 
from each atom. Finally, molprint2D is similar to the radial fingerprint and encodes the heavy atom environments by identifying the atom types positioned at different topological distances.

\section{Results}

\subsection{Chemical and Biological Landscape}

The dataset used to construct the ANN and KPLS models was selected from the literature and includes 363 structurally diverse compounds [26-64]. The trypanocidal activity of these molecules is expressed as the concentration of the compound that inhibits 50\% the growth of $T$. cruzi in phenotypic assays $\left(\mathrm{IC}_{50}\right)$. The $\mathrm{IC}_{50}$ values range from $2 \mathrm{nM}$ to $97.97 \mu \mathrm{M}$ (a 48,985-fold activity range) and were converted into $\mathrm{pIC}_{50}$ values $\left(-\log \mathrm{IC}_{50}\right)$ prior to the QSAR modeling. This wide activity interval follows the broad chemical diversity enclosed in the dataset. The structural and activity landscape covered by the 363 trypanocidal agents is illustrated in Figure 2. In the structure similarity map, the distance among the points is inversely proportional to the structural similarity, and the colors represent different activity ranges (Figure 2A). Based on this map, training and test sets were selected to construct the models. Structurally distinct chemotypes enclosing a wide spectrum of $\mathrm{PIC}_{50}$ values were included in both the training (280 compounds) and test sets ( 83 compounds), as depicted in Figure 2B,C.
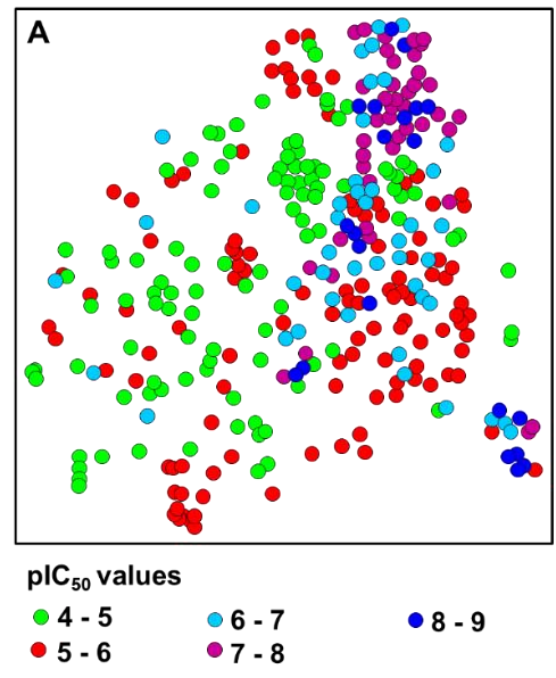

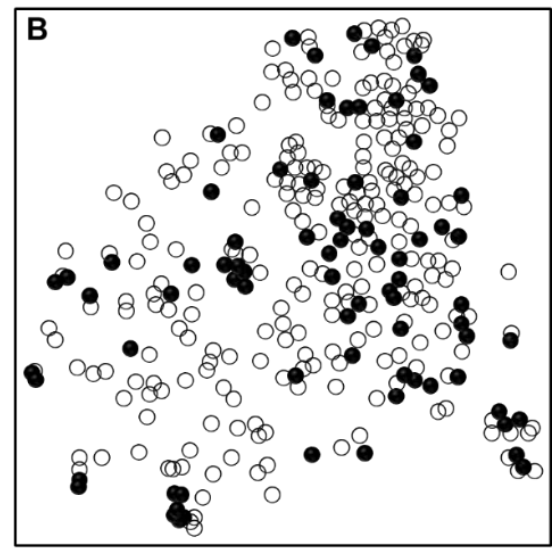

$\bigcirc$ Training set (280) $\quad$ Test set (83)

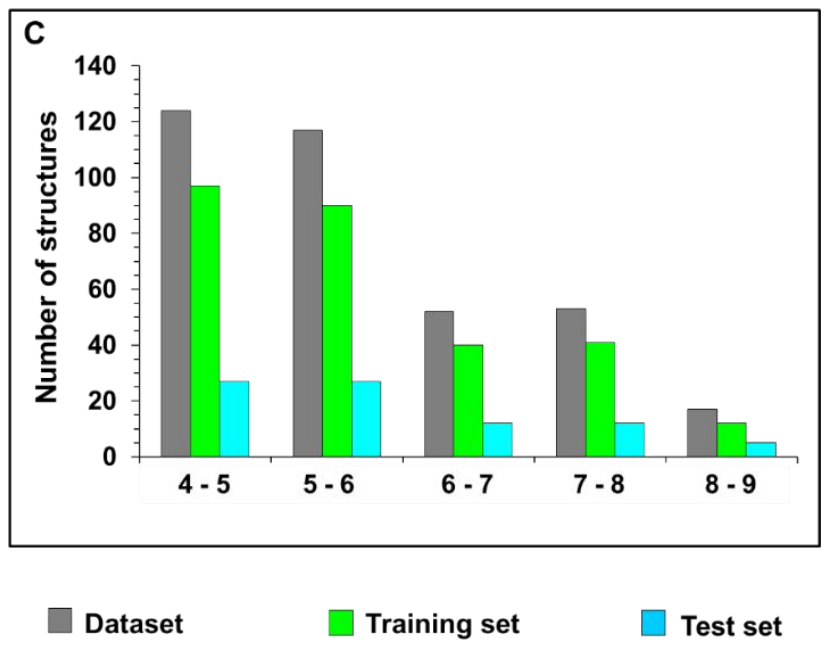

Figure 2. Structural and activity landscape of the dataset. (A) Structure similarity map for the entire dataset composed of 363 compounds, which shows its broad chemical diversity and activity range. (B) Structure similarity map highlighting the training (open circles) and test set (solid circles) compounds. (C) Activity distribution for the whole dataset and for the training and test sets. 


\subsection{Artificial Neural Networks}

Eleven physicochemical properties were used as molecular descriptors to build the ANNs through which the trypanocidal activity of the dataset compounds were predicted. Hence, prior to running the ANN analyses, the dataset was characterized with respect to its physicochemical profile. Figure 3 shows the distribution of the dataset regarding the following physicochemical descriptors: molecular weight $(\mathrm{MW})$, octanol-water partition coefficient $(a \log \mathrm{P})$, hydrogen bond acceptors (HBA), hydrogen bond donors (HBD), number of rotatable bonds (RB), and heavy atom count (HAC). Figure 4, in turn, shows the physicochemical profile of the dataset regarding ring count (RC), polar surface area (PSA), electrotopological state (E-state), molar refractivity (MR), and molecular polarizability (Polar).
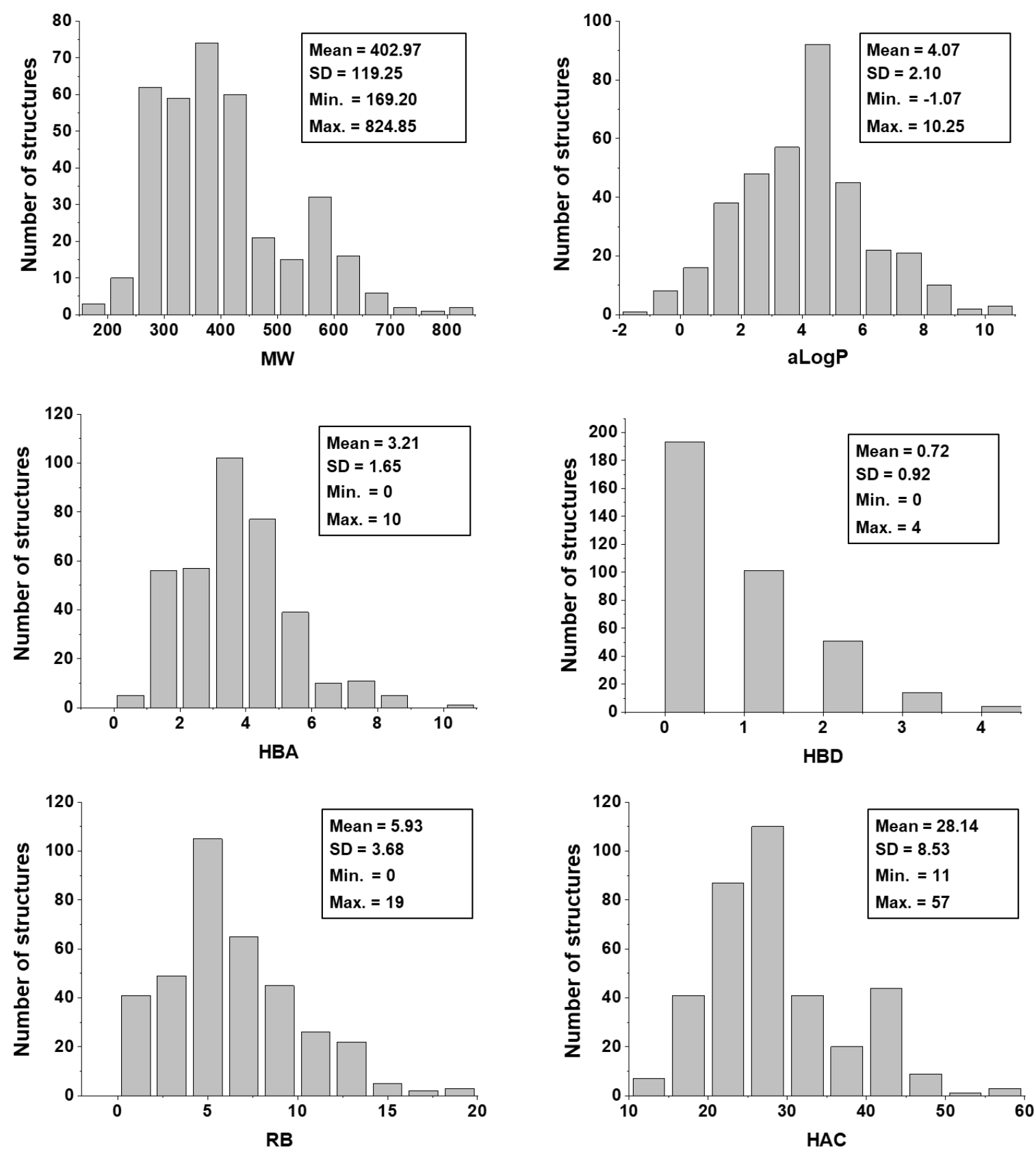

Figure 3. Distribution of physicochemical properties for the dataset. Note: MW = molecular weight; $a \log \mathrm{P}=\log$ arithm of the octanol-water partition coefficient; HBA = hydrogen bond acceptors; $\mathrm{HBD}=$ hydrogen bond donors; $\mathrm{RB}=$ number of rotatable bonds; HAC = heavy atom count; $\mathrm{SD}=$ standard deviation. 

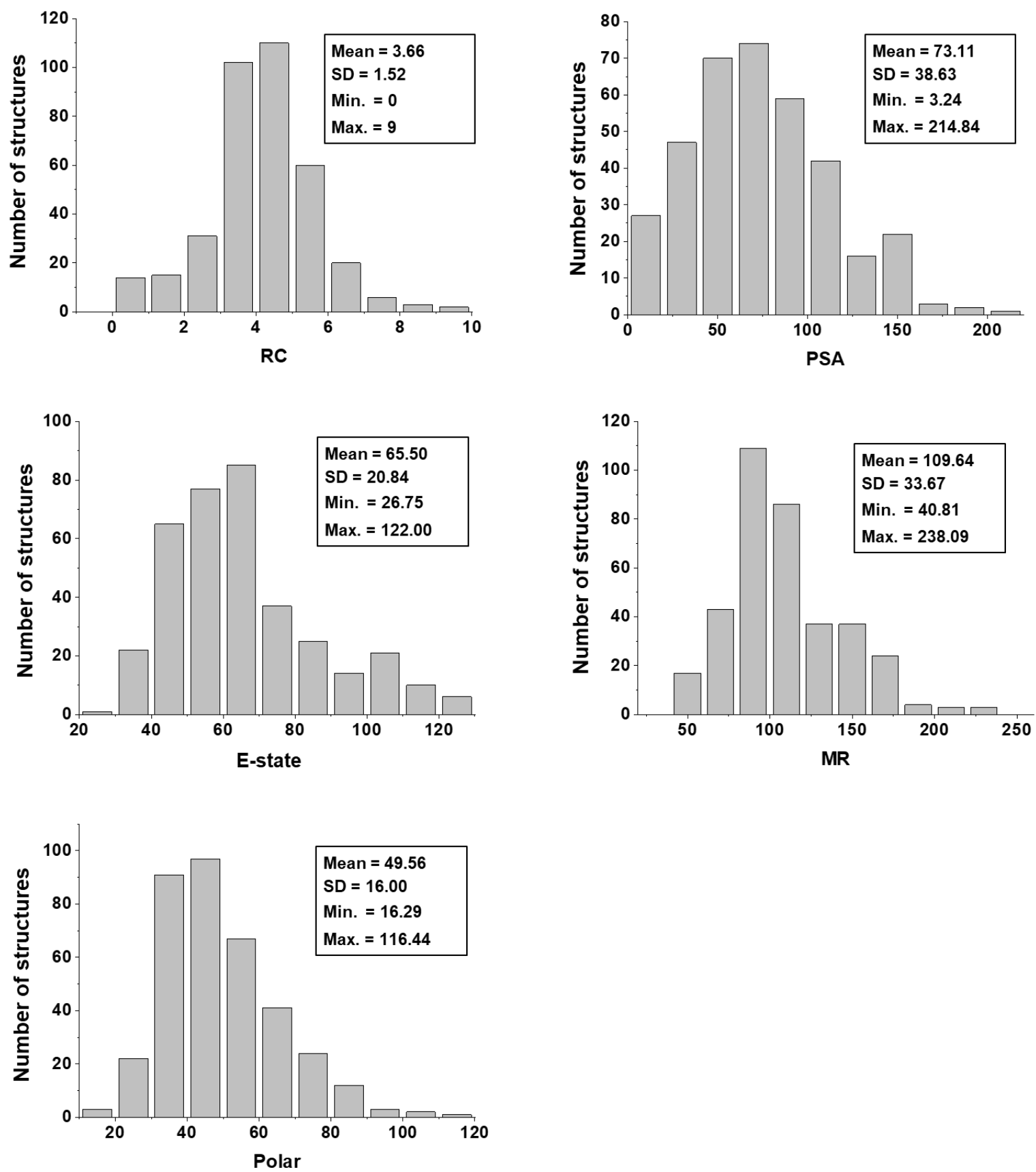

Figure 4. Physicochemical characterization of the dataset. Note: $\mathrm{RC}=$ ring count; PSA = polar surface area; E-state = electrotopological state; $\mathrm{MR}=$ molar refractivity; Polar = molecular polarizability; $\mathrm{SD}=$ standard deviation .

The calculated physicochemical descriptors for 280 training set compounds were used as inputs to build backpropagation ANNs. The predictive power of the models was additionally evaluated by using 83 test set molecules. Table 1 shows the performance of the ANNs as a function of the learning rate (LR). The score value was used as the leading parameter to evaluate the performance of the models. The top-scoring model, which was derived with an LR of 0.1 , presented a score of 0.80 . As the score is derived from the correlation coefficients, this model had good performance regarding these indicators for both the training and test sets $\left(r^{2}=0.79\right.$ and $\left.q^{2}=0.85\right)$. The $r^{2}$ value indicates the internal statistical robustness of the models considering the training set only. Otherwise, the $q^{2}$ value indicates the external predictive power, since it considers the performance of the models in predicting the dependent 
variables of molecules that were not used to train the algorithm. The score value represents the general performance of the models, considering both its internal and external predictive power.

Table 1. Performance of the ANNs as a function of the learning rate.

\begin{tabular}{cccccccccccc}
\hline \multicolumn{1}{c}{ Training Set } \\
\hline LR & Score & $\boldsymbol{r}^{2}$ & MAE & RMSE & RAE & RRSE & $\boldsymbol{q}^{2}$ & MAE & RMSE & RAE & RRSE \\
\hline 0.1 & 0.80 & 0.79 & 0.65 & 0.82 & 65 & 68 & 0.85 & 0.6 & 0.75 & 59 & 61 \\
0.2 & 0.76 & 0.80 & 0.58 & 0.76 & 59 & 64 & 0.78 & 0.66 & 0.84 & 65 & 68 \\
0.3 & 0.77 & 0.79 & 0.60 & 0.77 & 60 & 65 & 0.78 & 0.67 & 0.89 & 66 & 72 \\
0.4 & 0.75 & 0.80 & 0.58 & 0.77 & 59 & 64 & 0.77 & 0.69 & 0.94 & 68 & 76 \\
\hline
\end{tabular}

Note: $\mathrm{LR}=$ learning rate; $r^{2}=$ correlation coefficient for the training set; $q^{2}=$ correlation coefficient for the test set $\left(r_{\text {pred }}^{2}\right) ; \mathrm{RMSE}=$ root mean square error; MAE = mean absolute error; $\mathrm{RAE}=$ relative absolute error; $\mathrm{RRSE}=$ root relative squared error; score $=\left(1-\left|\left(r^{2}-q^{2}\right)\right|\right) \times q^{2}$.

Next, the momentum parameter (MP) of the backpropagation algorithm was varied for the top-scoring model of Table 1 . This procedure was conducted to search for the best convergence criterion and prevent the ANNs from converging to a local minimum. MP was varied from 0.1 to 0.4 in steps of 0.1 , and the resulting models are shown in Table 2. As seen, the variation of MP had no influence on the overall quality of the ANNs, as demonstrated by the resulting scores. Hence, the lowest RMSE values ( 0.82 and 0.75 for the training and test sets, respectively) were considered to select the model having an MP of 0.2 and a score of 0.80 for further optimization. Importantly, this model maintained good correlation coefficients for both the training $\left(r^{2}=0.79\right)$ and test sets $\left(q^{2}=0.85\right)$.

Table 2. Performance of the ANNs as a function of the momentum parameter.

\begin{tabular}{cccccccccccc}
\hline \multicolumn{1}{c}{ Training Set } \\
\hline MP & Score & $\boldsymbol{r}^{2}$ & MAE & RMSE & RAE & RRSE & $\boldsymbol{q}^{2}$ & MAE & RMSE & RAE & RRSE \\
\hline 0.1 & 0.79 & 0.78 & 0.64 & 0.81 & 64 & 68 & 0.84 & 0.58 & 0.73 & 57 & 59 \\
0.2 & 0.80 & 0.79 & 0.65 & 0.82 & 65 & 68 & 0.85 & 0.6 & 0.75 & 59 & 61 \\
0.3 & 0.80 & 0.79 & 0.66 & 0.83 & 66 & 70 & 0.85 & 0.62 & 0.77 & 61 & 63 \\
0.4 & 0.80 & 0.79 & 0.67 & 0.84 & 67 & 71 & 0.85 & 0.62 & 0.78 & 62 & 63 \\
\hline
\end{tabular}

Note: MP = momentum parameter; $r^{2}=$ correlation coefficient for the training set; $q^{2}=$ correlation coefficient for the test set $\left(r^{2}\right.$ pred $)$; RMSE = root mean square error; MAE = mean absolute error; RAE = relative absolute error; RRSE $=$ root relative squared error; score $=\left(1-\left|\left(r^{2}-q^{2}\right)\right|\right) \times q^{2}$.

Finally, we varied the number of neurons in the hidden layer from one to 10 , while maintaining the optimal values of LR (0.1) and MP (0.2). The best results were produced when seven neurons were added to the hidden layer, as shown in Table 3. A subtle improvement in the score (0.81) was observed in this model compared to the ANN containing the default number of six neurons in the hidden layer.

The statistical indicators shown in Table 3, particularly the correlation coefficient for the test compounds $\left(q^{2}=0.81\right)$, show the ability of the best ANN model to predict the trypanocidal activity of novel and structurally diverse compounds. The good agreement between the experimental and predicted $\mathrm{pIC}_{50}$ values exhibited by this model is graphically illustrated in Figure 5 for the training and test set compounds. 
Table 3. Performance of the ANNs as a function of the number of neurons in the hidden layer.

\begin{tabular}{cccccccccccc}
\hline \multicolumn{1}{c}{ Training Set } \\
\hline NN & Score & $\boldsymbol{r}^{2}$ & MAE & RMSE & RAE & RRSE & $\boldsymbol{q}^{2}$ & MAE & RMSE & RAE & RRSE \\
\hline 1 & - & 0.51 & 0.86 & 1.03 & 87 & 68 & - & - & - & - & - \\
2 & - & 0.72 & 0.69 & 0.85 & 69 & 72 & - & - & - & - & - \\
3 & - & 0.75 & 0.69 & 0.86 & 69 & 72 & - & - & - & - & - \\
4 & - & 0.77 & 0.68 & 0.84 & 68 & 70 & - & - & - & - & - \\
5 & 0.78 & 0.78 & 0.64 & 0.81 & 65 & 68 & 0.80 & 0.64 & 0.82 & 63 & 66 \\
$6^{\#}$ & 0.80 & 0.79 & 0.65 & 0.82 & 65 & 68 & 0.85 & 0.60 & 0.75 & 59 & 61 \\
7 & 0.81 & 0.81 & 0.57 & 0.73 & 56 & 62 & 0.81 & 0.59 & 0.76 & 58 & 62 \\
8 & 0.76 & 0.79 & 0.68 & 0.85 & 68 & 71 & 0.77 & 0.69 & 0.90 & 68 & 73 \\
9 & 0.80 & 0.80 & 0.65 & 0.82 & 65 & 68 & 0.82 & 0.64 & 0.81 & 63 & 66 \\
10 & 0.77 & 0.82 & 0.58 & 0.75 & 58 & 63 & 0.79 & 0.62 & 0.83 & 61 & 67 \\
\hline
\end{tabular}

Note: $\mathrm{NN}=$ number of neurons in the hidden layer; $r^{2}=$ correlation coefficient for the training set; $q^{2}=$ correlation coefficient for the test set $\left(r_{\text {pred }}^{2}\right)$; RMSE $=$ root mean square error; MAE $=$ mean absolute error; RAE = relative absolute error; RRSE $=$ root relative squared error; score $=\left(1-\left|\left(r^{2}-q^{2}\right)\right|\right) \times q^{2}$. " Standard NN.

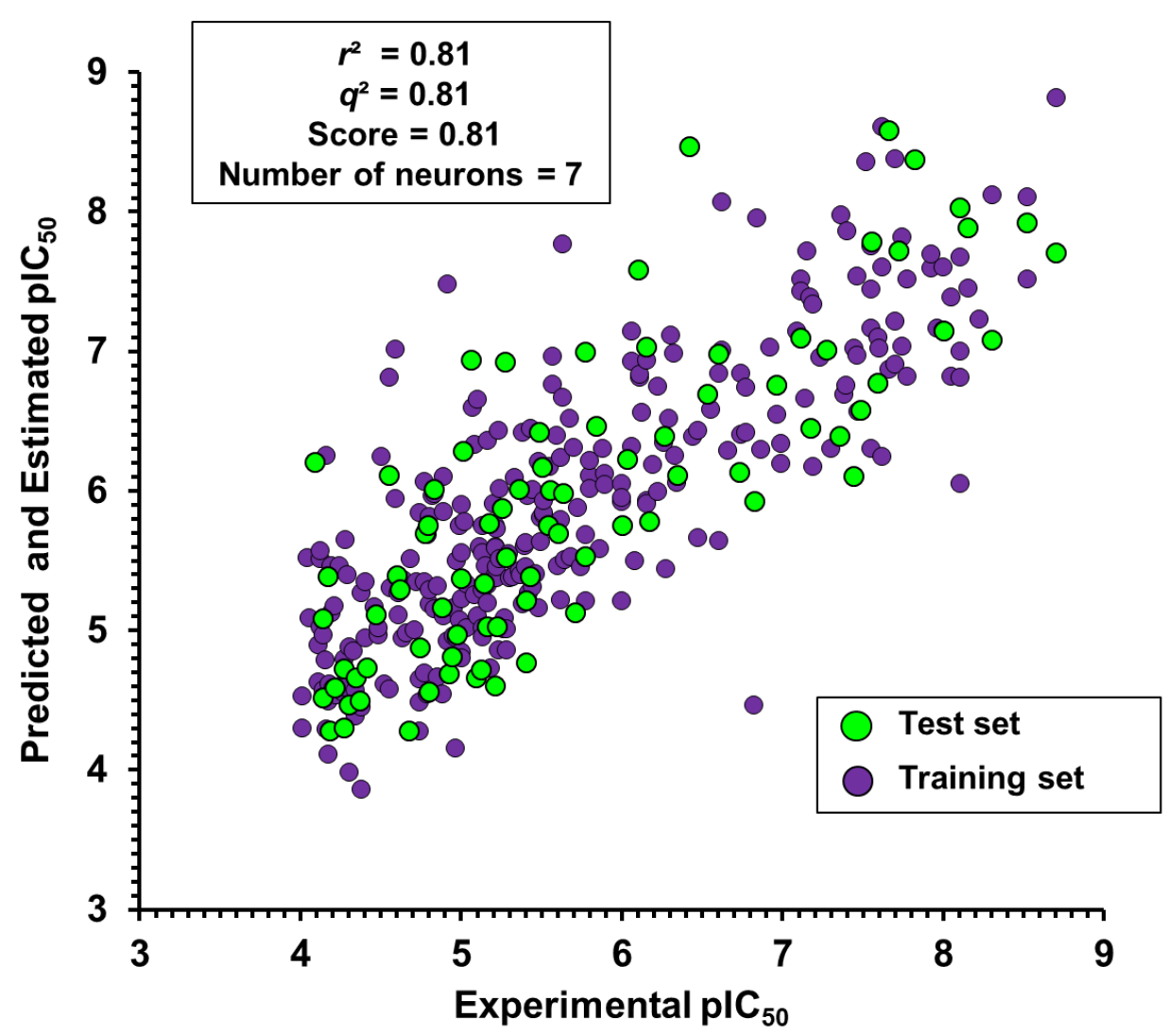

Figure 5. Experimental versus ANN-predicted values of trypanocidal activity $\left(\mathrm{pIC}_{50}\right)$.

Impact of the Physicochemical Properties on the Trypanocidal Activity

Given the high predictive power of the best ANN (seven neurons in the hidden layer, Table 3), we investigated the role played by each physicochemical descriptor on the trypanocidal activity of the dataset compounds. Each molecular descriptor works as an input applied to the ANN neurons. These descriptors are weighted by an activation function at each neuron, which is responsible for processing and transmitting the signal to the other neurons. These weights can be positive or negative. A positive weight attributed to a given physicochemical descriptor leads to a proportional increase in biological activity; that is, increasing the value of the weight increases the activity, and decreasing this 
value decreases the biological activity. Otherwise, negative weights lead to an inversely proportional neuron response, i.e., decreasing the weight value increases the biological activity, and increasing this value decreases the activity.

Table 4 shows the weights of each molecular descriptor at each hidden-layer neuron. Among the 11 descriptors, MW showed the greatest difference between the number of positively and negatively weighted neurons. Six neurons had their activation function positively weighted by MW; for most neurons, increments in this property resulted in increased trypanocidal activity. In the second position came $a \log$, HBA, HBD, and MR, which positively weighted five out of the seven hidden-layer neurons. The reciprocal ratio was observed for RB, that is, five neurons produced negative values. HAC, RC, and Polar positively weighted four neurons, whereas PSA and E-state showed the inverse ratio, i.e., they negatively weighted four hidden-layer neurons.

Table 4. Weights attributed to each physicochemical descriptor at the individual hidden-layer neurons.

\begin{tabular}{cccccccccccc}
\hline Neuron & MW & $a$ LogP & HBA & HBD & RB & HAC & RC & PSA & E-state & MR & Polar \\
\hline 1 & 0.51 & 1.94 & 0.90 & 3.34 & 0.73 & 0.46 & -0.27 & -0.28 & -0.34 & 0.99 & 0.59 \\
2 & 2.77 & -3.96 & -2.61 & -0.11 & -0.23 & 2.98 & -2.21 & -2.82 & 1.04 & 2.39 & 3.68 \\
3 & -1.42 & 1.79 & 0.49 & 2.12 & -0.33 & -0.20 & 2.44 & 1.55 & -0.28 & -1.07 & -0.60 \\
4 & 0.59 & 0.06 & 0.07 & 1.05 & 0.14 & 0.29 & 0.44 & 0.31 & 0.25 & 0.06 & 0.76 \\
5 & 1.39 & -4.91 & -6.71 & -0.28 & -0.79 & 3.33 & 4.58 & 1.08 & -0.20 & 4.85 & 5.49 \\
6 & 0.55 & 2.75 & 0.94 & 3.22 & -2.00 & -0.55 & 0.66 & -5.24 & -3.30 & 1.49 & -0.76 \\
7 & 1.60 & 3.78 & 5.40 & 2.38 & -2.72 & -2.20 & -2.52 & -0.14 & 0.92 & -1.10 & -2.80 \\
\hline
\end{tabular}

Note: $\mathrm{MW}=$ molecular weight; $a \log \mathrm{P}=$ logarithm of the octanol-water partition coefficient; HBA = hydrogen bond acceptors; $\mathrm{HBD}=$ hydrogen bond donors; $\mathrm{RB}=$ number of rotatable bonds; $\mathrm{HAC}=$ heavy atom count; $\mathrm{RC}=$ ring count; PSA = polar surface area; E-state = electrotopological state; $\mathrm{MR}=$ molar refractivity; Polar = molecular polarizability.

\subsection{Kernel-Based Partial Least Squares}

Four molecular fingerprint types (dendritic, linear, molprint2D, and radial) were used as molecular descriptors to generate the 2D QSAR models. These descriptors were correlated with the trypanocidal activity of the dataset compounds using KPLS regression. The statistical indicators for the best models generated with each descriptor are presented in Table 5. All fingerprint types produced models with a similar prediction ability for the test set, with molprint2D performing slightly better $\left(q^{2}=0.84\right)$. For the training set, the best correlation coefficients were produced by models generated with dendritic and linear fingerprints $\left(r^{2}=0.89\right)$. The highest score, which is the result of the combination of $q^{2}$ and $r^{2}$, was produced by the molprint2D-model (score $=0.82$ ). Figure 6 illustrates the good alignment between the experimental and predicted $\mathrm{pIC}_{50}$ values produced by the molprint2D-model. Considering these results, this model was selected to investigate how the structure of the dataset compounds correlate with the trypanocidal activity.

Table 5. Model performance as a function of the fingerprint types used as molecular descriptors to build the kernel-based partial least squares (KPLS) models.

\begin{tabular}{ccccccc}
\hline Fingerprint & Score & $\boldsymbol{q}^{\mathbf{2}}$ & $\boldsymbol{r}^{\mathbf{2}}$ & RMSE & SD & $\mathbf{N}$ \\
\hline Dendritic & 0.76 & 0.82 & 0.89 & 0.40 & 0.53 & 3 \\
Linear & 0.78 & 0.83 & 0.89 & 0.41 & 0.51 & 3 \\
Radial & 0.80 & 0.81 & 0.80 & 0.54 & 0.54 & 2 \\
Molprint2D & 0.82 & 0.84 & 0.81 & 0.52 & 0.50 & 3 \\
\hline
\end{tabular}

Note: $q^{2}=$ correlation coefficient for the test set $\left(r^{2}\right.$ pred $) ; r^{2}=$ correlation coefficient for the training set; RMSE = root mean square error; $\mathrm{SD}=$ standard deviation; $\mathrm{N}=$ number of components; score $=\left(1-\left|\left(r^{2}-q^{2}\right)\right|\right) \times q^{2}$. 


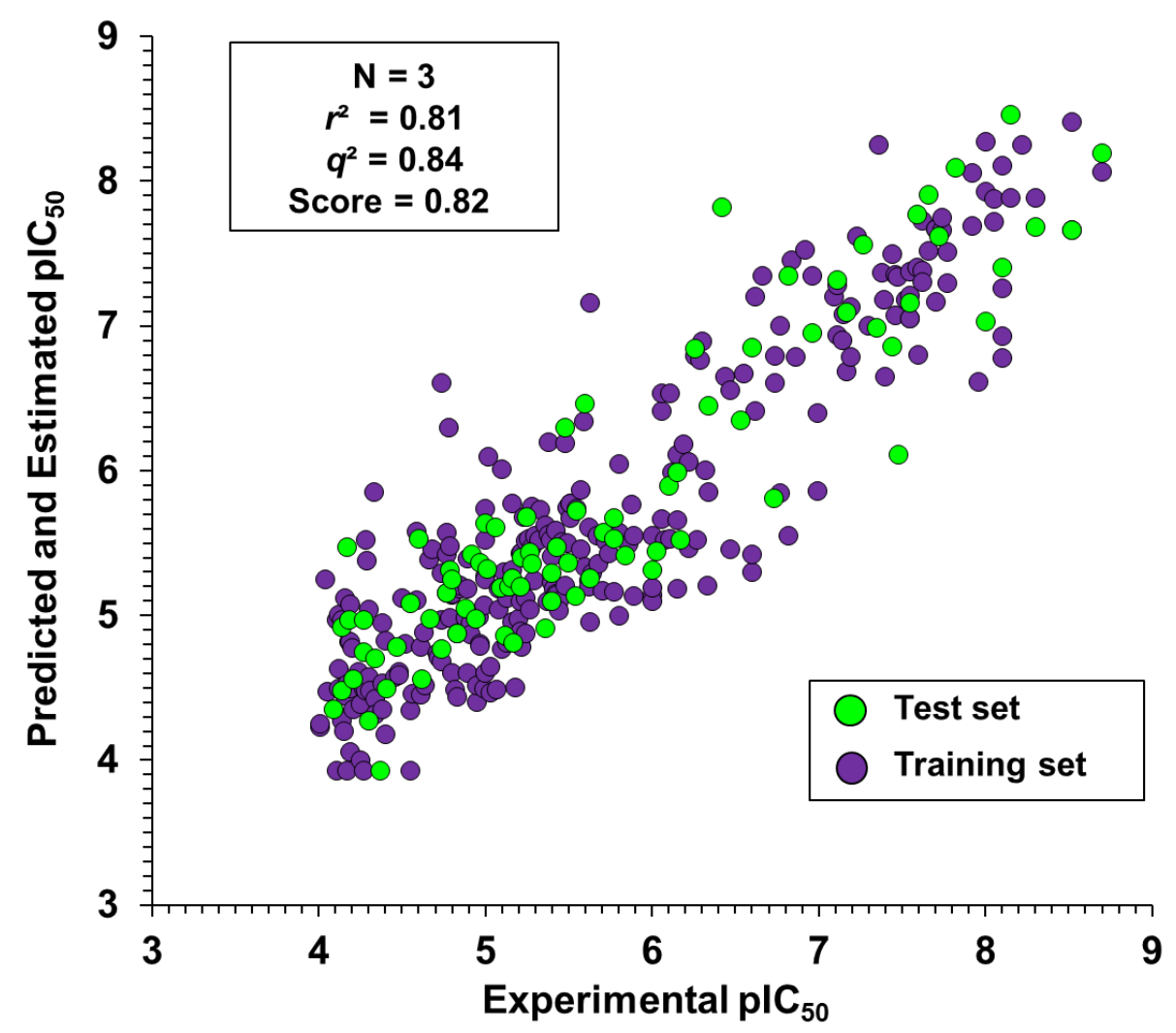

Figure 6. Experimental versus KPLS-predicted values of trypanocidal activity $\left(\mathrm{pIC}_{50}\right)$.

\section{Contribution Maps}

KPLS models can be assessed for favorable and unfavorable structural characteristics through the generation of atomic contribution maps. Hence, the most relevant structural features for the trypanocidal activity were investigated by generating contribution maps based on the best KPLS model (molprint2D, Table 5). Positive, neutral, and negative contributions are depicted in red, white, and blue, respectively, and the color intensity shows the magnitude of the effect (Figure 7). Overall, heterocyclic aromatic rings contributed positively to activity. Aliphatic hydrocarbon chains showed negative or no influence for most compounds. Halogen substituents showed the full range of contributions-fluorine contributed positively, chlorine and iodine had no influence, and bromine contributed negatively. In general, hydroxyl groups were unfavorable, and piperazine rings were demonstrated to be favorable. 


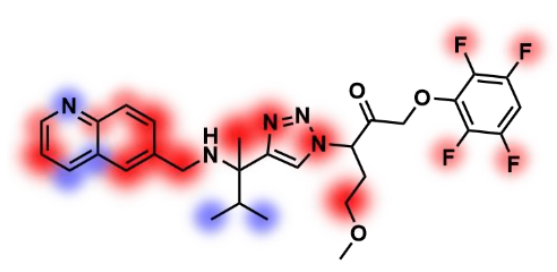

(3) $\mathrm{plC}_{50}=8.70$

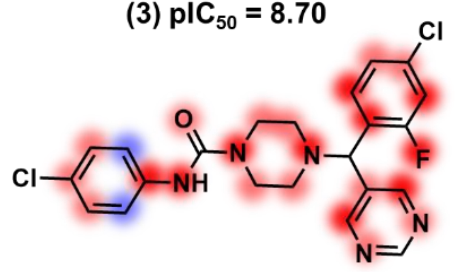

(6) $\mathrm{plC}_{50}=8.00$

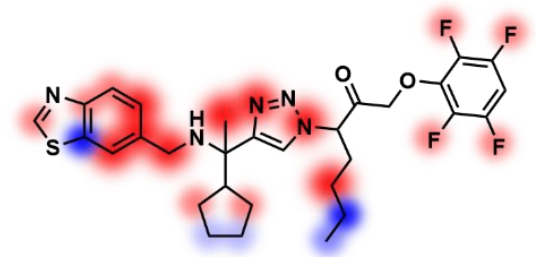

(4) $\mathrm{plC}_{50}=8.52$

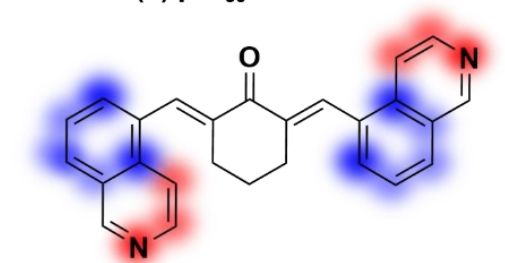

(7) $\mathrm{plC}_{50}=4.16$

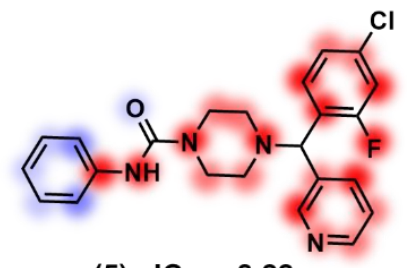

(5) $\mathrm{plC}_{50}=8.22$

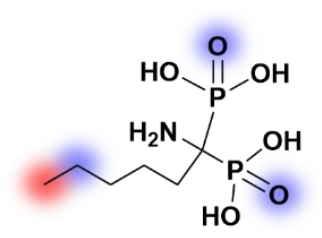

(8) $\mathrm{plC}_{50}=4.11$

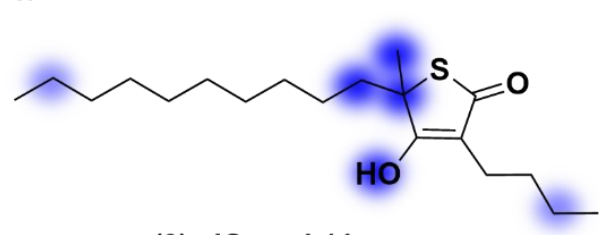

(9) $\mathrm{plC}_{50}=4.11$

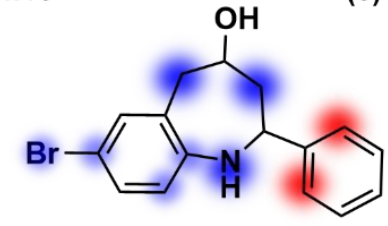

(10) $\mathrm{plC}_{50}=4.01$

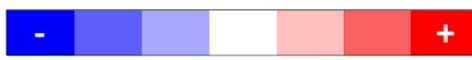

Figure 7. Contribution maps based on the molprint2D model (Table 5) for some dataset compounds located at both ends of the trypanocidal activity range.

\section{Physicochemical Profile of Favorable Fragments}

Twenty-nine active compounds with $\mathrm{pIC}_{50}>6$ (see Table $\mathrm{S} 1$ for the structures) were selected to construct a collection of 50 fragments. Only molecular fragments that were predicted to enhance the trypanocidal activity (red areas of the contribution maps) were considered in this analysis. Next, physicochemical descriptors were calculated for these fragments and used as an input for the best ANN with the view of predicting their biological activity. Finally, the predicted activity values were correlated with each physicochemical property of the fragment collection. The outcome of this analysis is illustrated as heat maps (Figures $8-10$ ), which allowed us to identify a specific physicochemical space that favors trypanocidal activity. The heat maps also correlate the activity of the compounds from which the fragments were extracted and their physicochemical profile.

Figure 8 shows the heat maps for MW, $a$ LogP, HBD, and HBA. Fragments with MW greater than $260 \mathrm{Da}$ were predicted to be the most active $\left(\mathrm{pIC}_{50}>6\right)$. For $a \log \mathrm{P}$, the most active fragments had values predominantly between 2 and 3. Fragments with $0-1 \mathrm{HBD}$ and 1-6 HBAs were predicted to have the highest $\mathrm{PIC}_{50}$ values. Figure 9 illustrates the heat maps for $\mathrm{HAC}, \mathrm{RB}, \mathrm{RC}$, and PSA. As shown in the figure, fragments with $\mathrm{HAC}$ values greater than 20 had the highest $\mathrm{pIC}_{50}$ values. For $\mathrm{RB}$, fragments with two to eight rotatable bonds were the most active. According to the heat maps, fragments with RC values from 2 to 3 were predicted to have the best anti-T. cruzi profile. Finally, fragments with polar surface area (PSA) predominantly between 50 and $80 \AA^{2}$ had the highest $\mathrm{pIC}_{50}$ values. Figure 10 shows the heat maps for E-state, MR, and Polar. The ANN predicted the fragments with E-state values between 35 and 63 as being the most active. Fragments with MR ranging from 65 to 115 were predicted to have the highest $\mathrm{pIC}_{50}$ values. Finally, the Polar descriptor was demonstrated to have optimal values ranging from 30 to 53 . 

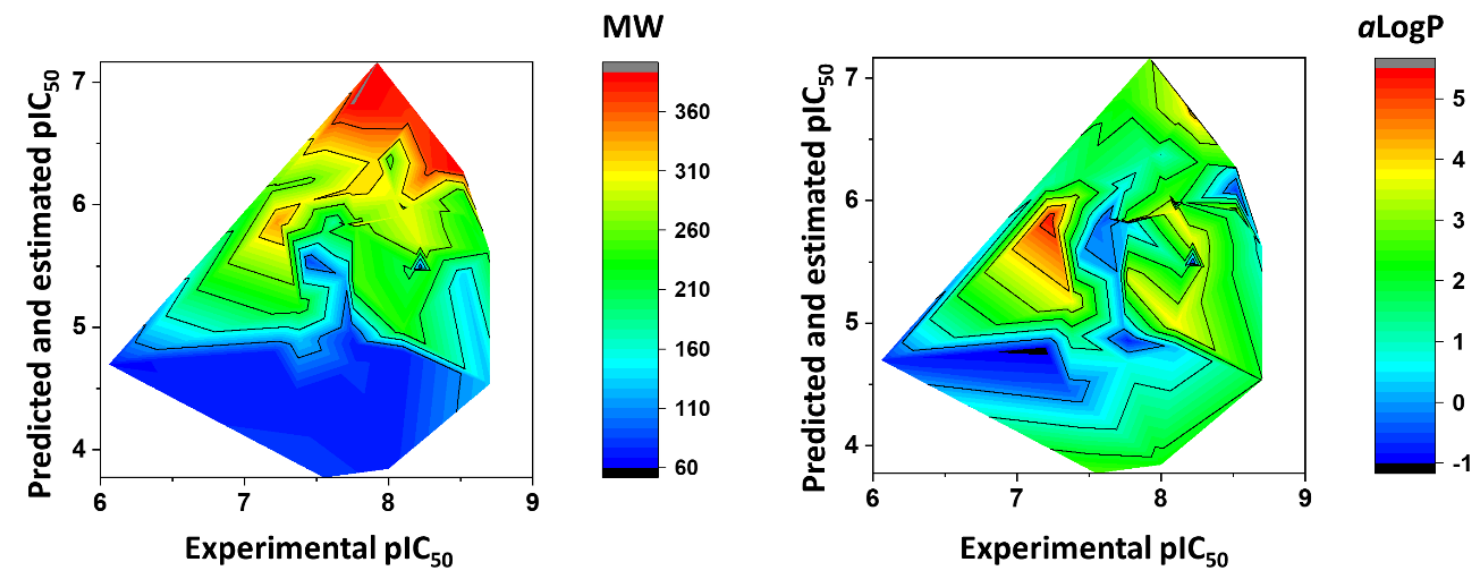

HBD
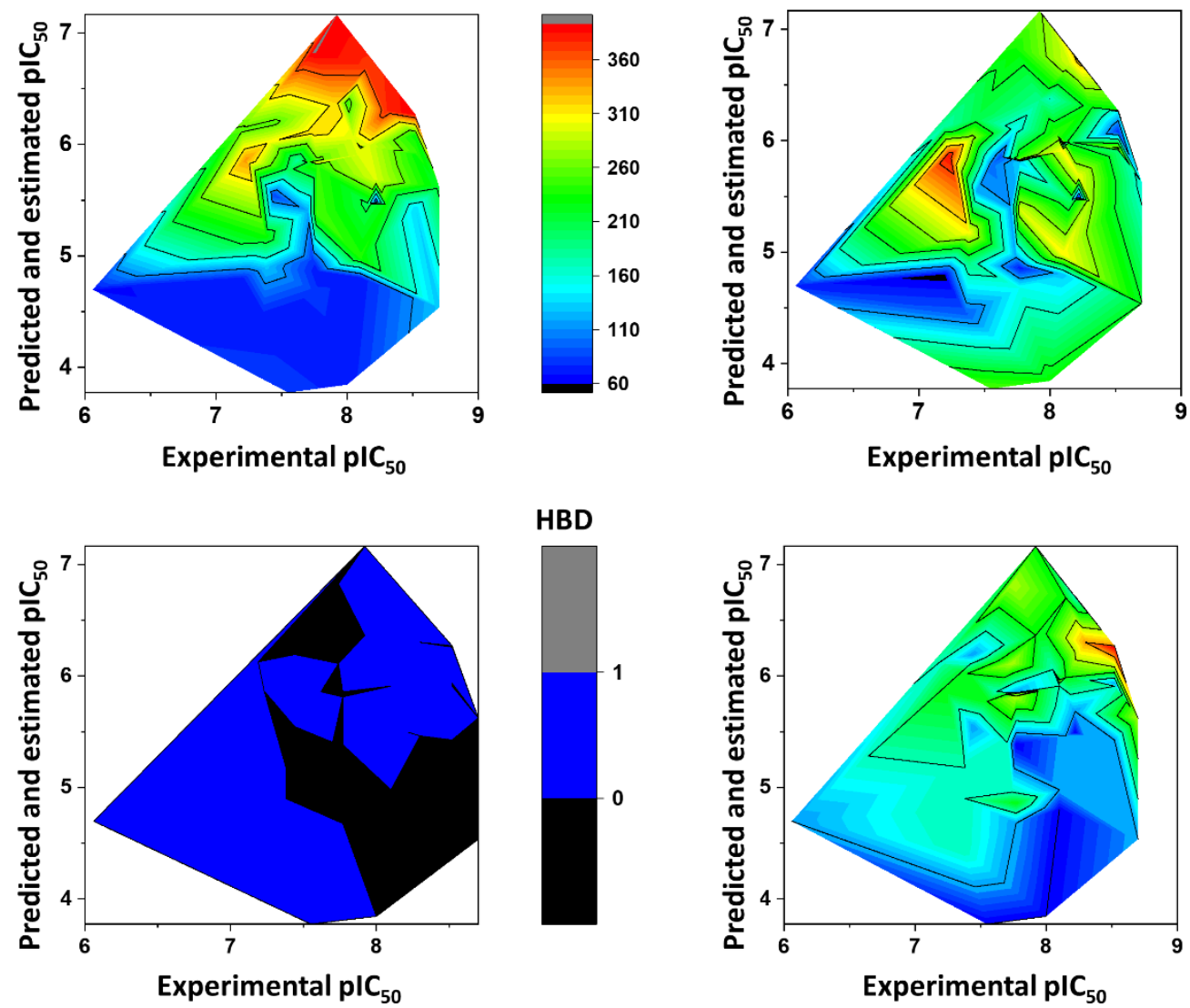

HBA
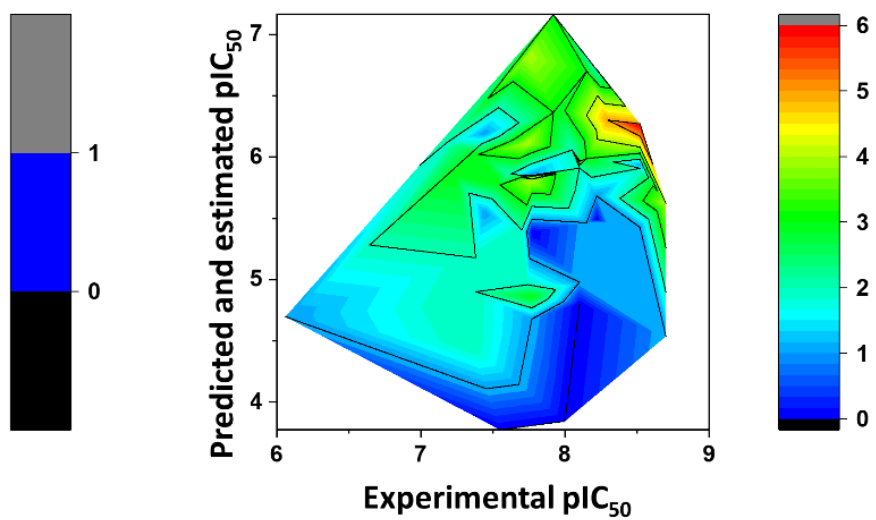

Figure 8. Heat maps showing the correlation between physicochemical properties and biological activity for molecular fragments extracted from the dataset. Note: $\mathrm{MW}=$ molecular weight; $a \mathrm{LogP}=$ octanol-water partition coefficient; HBD = hydrogen bond donors; HBA = hydrogen bond acceptors.

Figure 11 shows the structure and biological activity of 35 fragments that were predicted to be the most promising according to their trypanocidal profile. This group is characterized by a diversity of chemical motifs having two to four rings with the predominant groups being pyridine, pyrimidine, benzene, piperazine, triazole, benzothiazole, benzofuran, oxadiazole, and pyrazolopyrimidine. The four most active fragments from this collection have a phenylsulfonyl-piperazine (fragments 11 and 12) or a phenylpiperazine-carboxamide moiety (fragments 13 and 14) linked to two aromatic rings that are either pyridine, pyrimidine, or benzene. Replacing one of these aromatic rings with a hydrogen, such as in 16 and 22, led to a reduction of the biological activity. The same effect was observed for 24 and 27, in which one aromatic ring was kept and the benzene was replaced with a hydrogen. The replacement of the pyridine in compound 20 with a pyrimidine in compound 21 led to a subtle lowering of the $\mathrm{pIC}_{50}$ value. Another substitution that affected the biological activity was the exchange between the benzofuran, benzothiazole, and pyrazolopyrimidine in fragments 17, 18, and 19. Among these three compounds, the benzofuran derivative was the most potent. Furthermore, replacing the pyrazolopyrimidine in compound 23 with a benzothiazole in compound 15 increased the trypanocidal activity. 


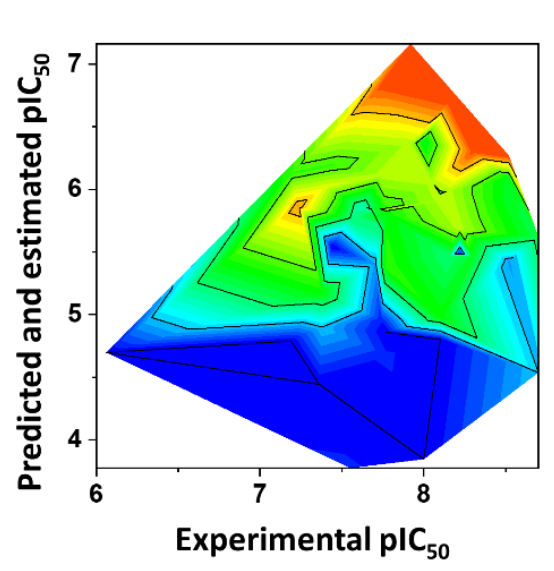

HAC
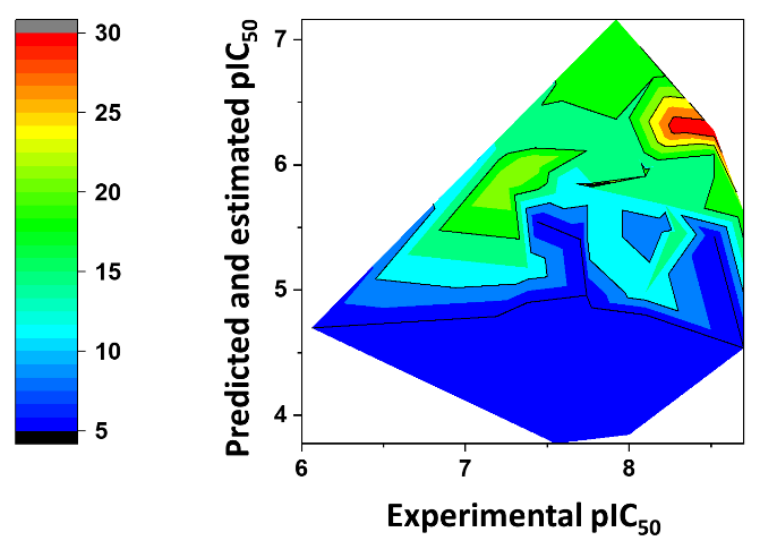

RB

RC
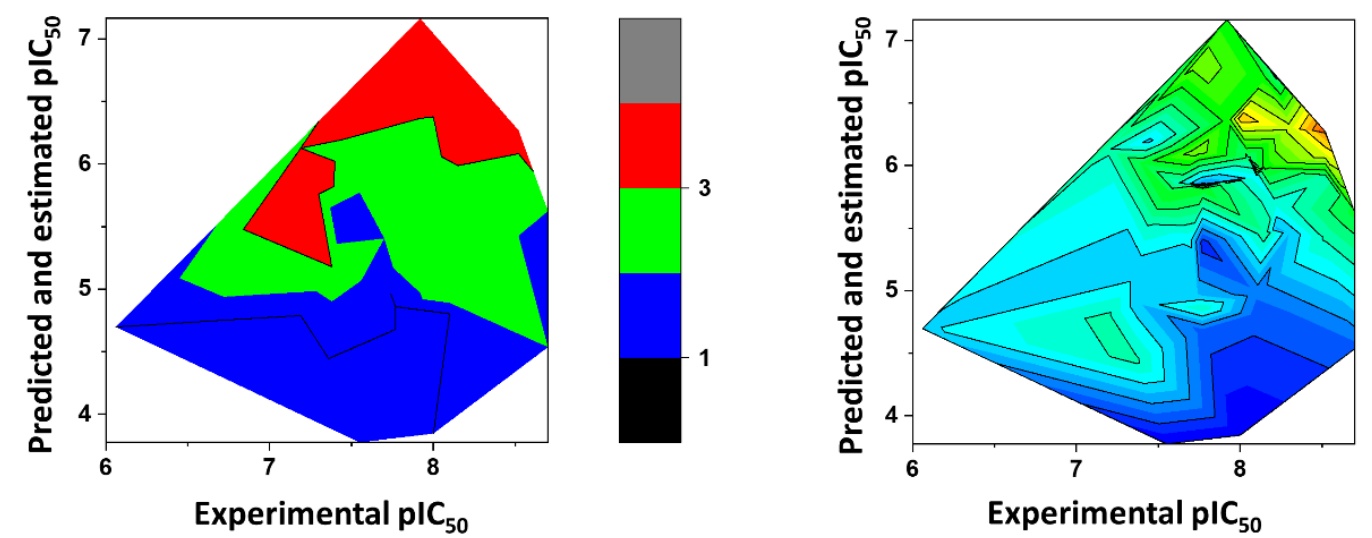

PSA
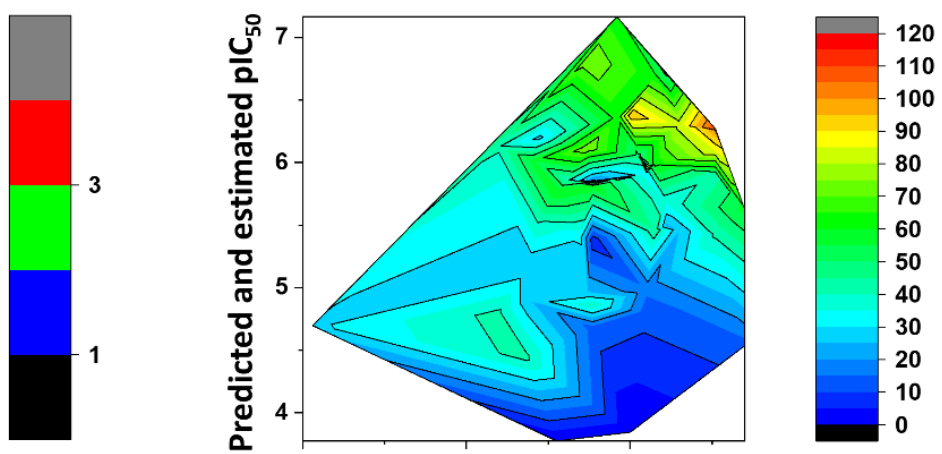

Figure 9. Heat maps showing the correlation between physicochemical properties and biological activity for molecular fragments extracted from the dataset. Note: HAC = heavy-atom count; RB = number of rotatable bonds; $\mathrm{RC}=$ ring count; PSA = polar surface area.

After analyzing the other molecular scaffolds, it is worth mentioning that for fragments 37 and 38 , it was not possible to establish a direct relationship between the presence of the oxadiazole group and trypanocidal activity. Replacing the oxadiazole in compound 37 with a phenyl in 44 decreased the $\mathrm{pIC}_{50}$ value; however, the same modification involving fragments 35 and 38 produced the opposite effect. Among cyclopentane derivatives 30, 32, and 43, replacing the benzothiazole in fragment 30 with pyrazolopyrimidine and benzofuran in 32 and 43, respectively, decreased the biological activity; the most significant effect occurred for the benzothiazole-benzofuran exchange, which resulted in a decrease of 0.47 in the $\mathrm{pIC}_{50}$ value. Finally, the insertion of a methyl cyclopentane moiety at the triazole ring of 41 resulted in fragment 36 and increased the trypanocidal activity. Figure 12 shows the overall scheme for the design of novel trypanocidal compounds based on the workflow proposed in this work. 


\section{E-state}
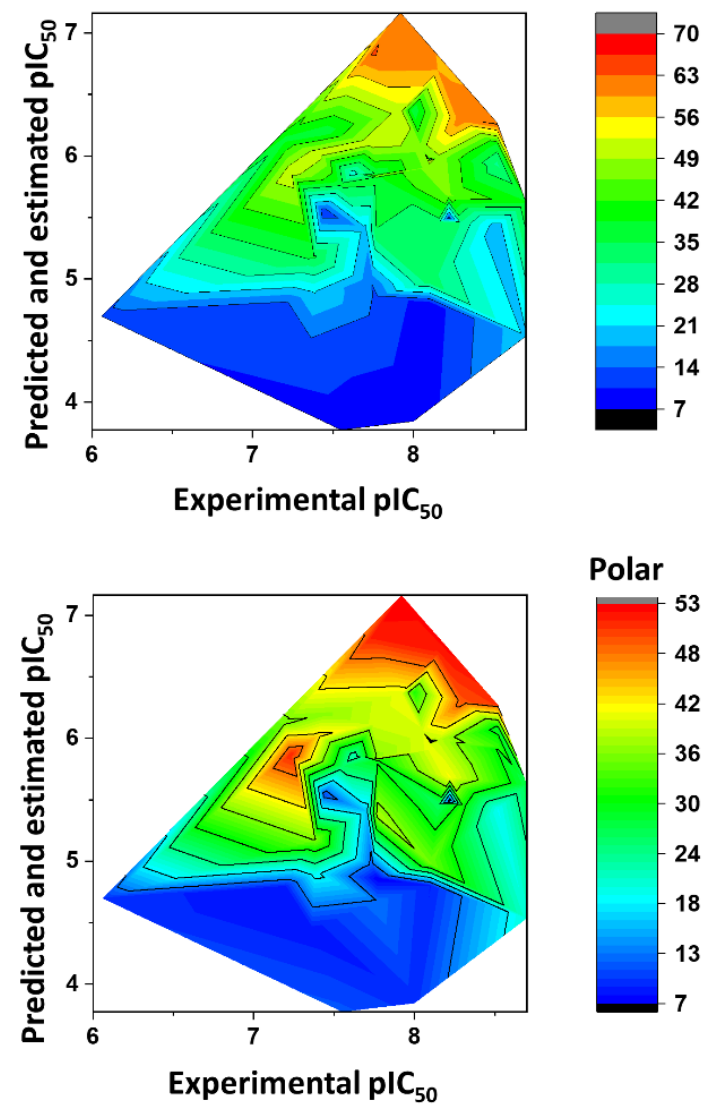

MR

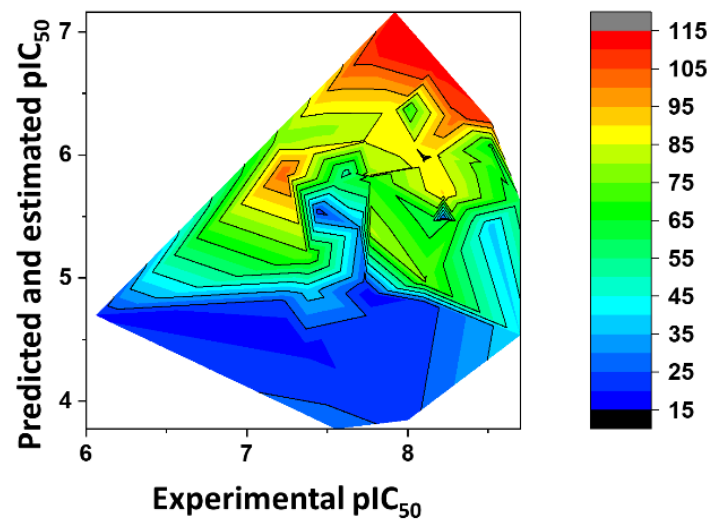

Figure 10. Heat maps showing the correlation between physicochemical properties and biological activity for molecular fragments extracted from the dataset. Note: E-state = electrotopological state; $\mathrm{MR}=$ molar refractivity Polar $=$ molecular polarizability. 

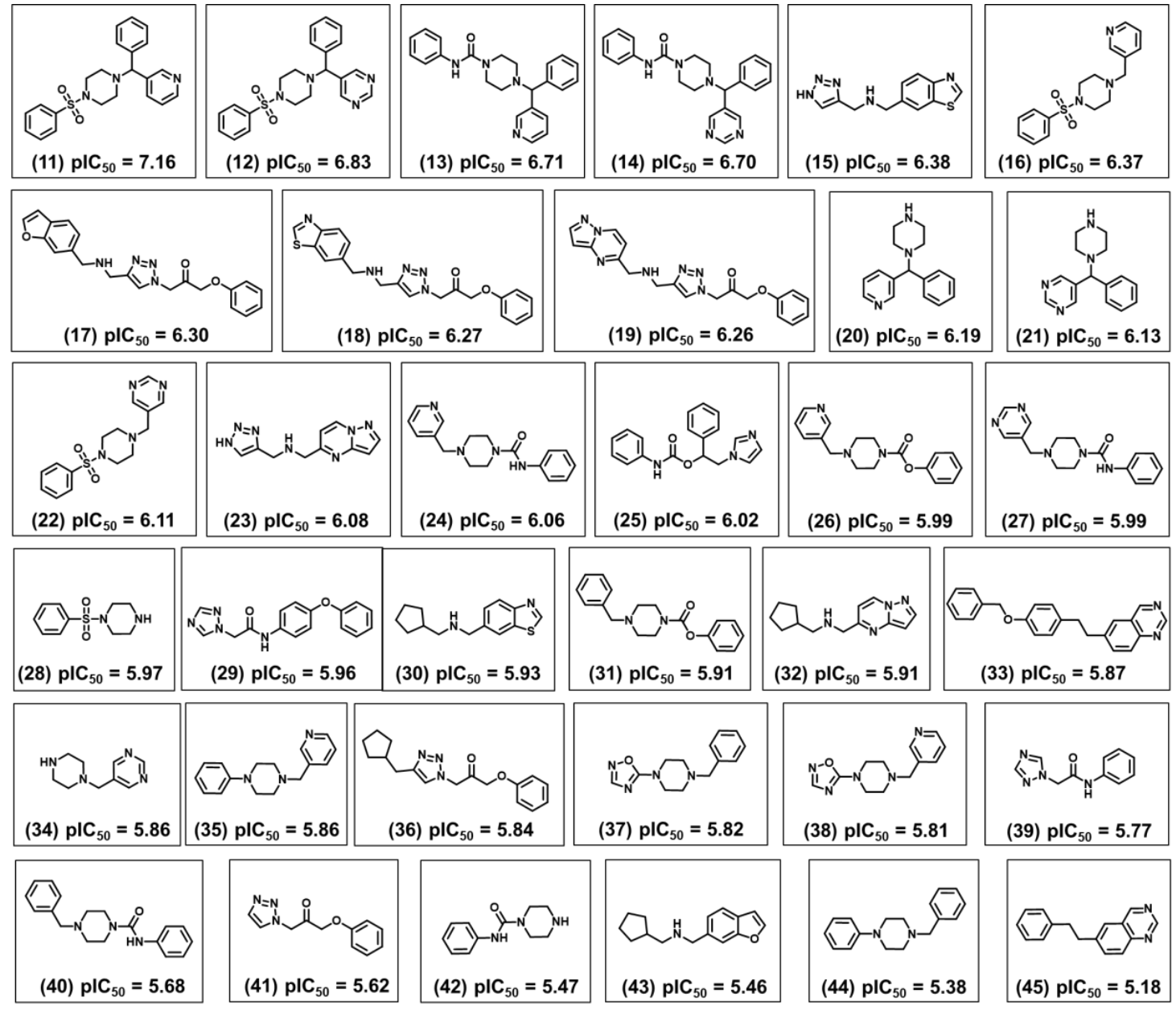

Figure 11. Fragments extracted from active compounds $\left(\mathrm{pIC}_{50}>6\right)$ and the respective $\mathrm{ANN}$-predicted trypanocidal activity.

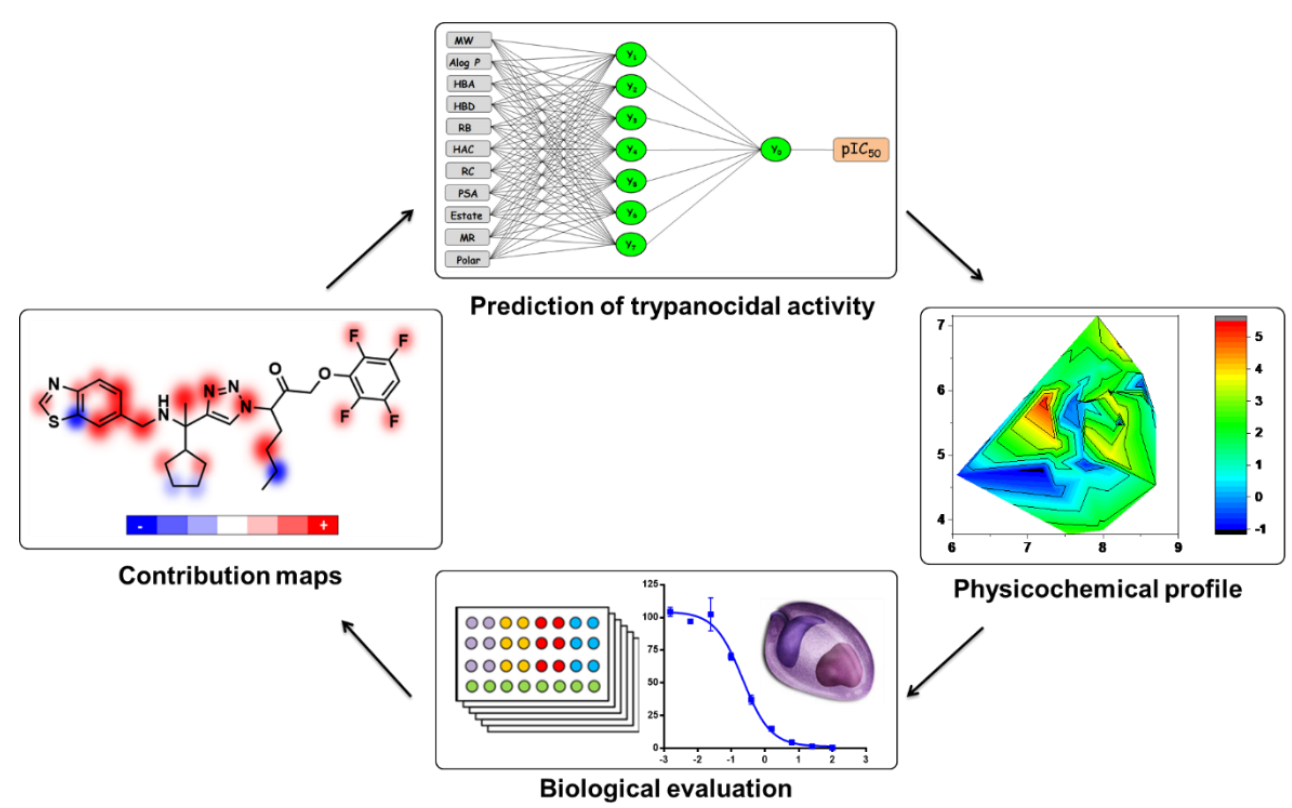

Figure 12. Proposed workflow for the design of novel anti-Trypanosoma cruzi compounds based on the generation of contribution maps, prediction of trypanocidal activity using artificial neural networks, and analysis of physicochemical properties. Compounds featuring favorable properties can be synthesized and evaluated against the parasite. 


\section{Discussion}

The physicochemical characterization of the dataset revealed that most compounds follow the Lipinski's Rule of Five, as illustrated in Figure 3 [65]. The determinant role played by these properties was shown by the analysis of the weights that were attributed to each physicochemical descriptor at the hidden-layer neurons of the best ANN (Table 4). MW, $a \operatorname{LogP}, \mathrm{HBA}$, and HBD exhibited the greatest difference between the number of positively and negatively modulated neurons. MW positively weighted six $(85.7 \%)$ out of the seven hidden-layer neurons, and $a$ LogP, HBA, and HBD positively weighted five $(71.4 \%)$ neurons. These four descriptors are closely related to bioavailability and the ability to permeate cell membranes, and therefore, the capacity of a compound to reach its molecular target. The number of rotatable bonds, which had a mean value of 5.93 for the whole dataset, also modulated most neurons in the same way- $71.4 \%$ of the hidden-layer neurons were negatively weighted by this property. HAC and RC positively weighted four out of seven hidden-layer neurons. The predominantly positive weighting profile of HAC and RC can be associated with that of MW and $a \log \mathrm{P}$; an increase in the first two properties generally leads to an increase in the latter two. Another finding worth mentioning is that the KPLS models led to the identification of a set of fragments that are strongly associated with enhanced trypanocidal activity. Most of these fragments contain between two and three rings, which follows the physicochemical profile identified by the ANN and shown in the heat maps for these chemotypes (Figure 9). Aromatic nitrogen-containing rings and fused rings are the most common structural features identified within this collection. Cyclopentane and piperazine are the only representants of aliphatic rings. Functionalized short linkers (from one to four atoms) containing amine, amide, sulfone, or ester groups are found between the cyclic groups. Nonfunctionalized linkers are almost exclusively restricted to methylene groups. Another aspect disclosed in this study was that the heat maps for the favorable fragments showed a more restricted physicochemical space compared to the results for the full molecules. For example, the following physicochemical ranges were predicted to be the most adequate for the fragment collection: MW > 260 Da; $a$ LogP: 2-3; PSA: 50-80 $\AA^{2}$; E-state: 35-63; MR: 65-115; and Polar: 30-53. These findings can be useful guidelines for monitoring the physicochemical profile in Chagas' disease drug design efforts using fragment-like compounds as starting points.

\section{Materials and Methods}

\subsection{Selection and Construction of the Dataset}

The 363 dataset compounds were selected from 39 articles from the Web of Science after eliminating compounds lacking $\mathrm{IC}_{50}$ values, and duplicated, inorganic, and metal-containing molecules [26-64]. All structures were built using the default settings of Canvas 2.9 (Schrodinger LLC, New York, NY, USA) [66]. IC 50 values were converted to $\mathrm{pIC}_{50}\left(-\log \mathrm{IC}_{50}\right)$. The 363 dataset compounds are available in the supporting information (Table S1).

\subsection{Characterization of the Chemical and Biological Space}

To characterize the structural and activity landscape of the dataset, we carried out a principal component analysis (PCA) using SYBYL-X 2.0 and UNITY fingerprints as molecular descriptors (Certara, Princeton, NJ, USA) $[67,68]$. The PCA result was converted into a structure similarity map that provides information on the structure and activity profiles of the dataset. To generate the structure similarity map, two principal components were initially extracted and applied as initial coordinates of the map. Next, Tanimoto distances between the molecular fingerprints were computed to plot all points of the map. Based on the structure similarity map, we selected the training ( 280 structures) and test (83 structures) sets to run the QSAR analyses. The training and test set molecules are available in the supporting information (Table S1). 


\subsection{Physicochemical Descriptors}

The physicochemical properties used as input to the ANNs were calculated using Canvas 2.9 (Schrodinger LLC, New York, NY, USA) [66]. The following descriptors were calculated: MW, $a$ LogP, HBD, HBA, RB, PSA, E-state, MR, Polar, HAC, and RC.

\subsection{Backpropagation Artificial Neural Networks}

The ANNs were built using the machine learning environment of WEKA 3.6 (University of Waikato, Hamilton, New Zealand) [69]. The calculated physicochemical descriptors and $\mathrm{pIC}_{50}$ values for the training set were used to train the ANNs [22]. The ANNs were built using the multilayer backpropagation perceptron and a logistic activation function [70]. After the weights were initially determined for each descriptor and the $\mathrm{pIC}_{50}$ values were predicted, the errors between the experimental and predicted values were used to update the weights for the first intermediate layer [23]. During this procedure, the adjustment of the activation function was performed through the partial derivative of the weights. Variations in the learning rate (0.1-0.4), momentum (0.1-0.4), and number of neurons (1-10) were explored to optimize the ANNs.

\subsection{Molecular Fingerprints and 2D Contribution Maps}

The KPLS models were constructed for the training set using Canvas molecular fingerprints (Schrodinger LLC, New York, NY, USA) as molecular descriptors [66]. Four types of fingerprints were explored: linear, dendritic, radial, and molprint2D [24,25,71]. The best KPLS model, which was obtained with molprint2D descriptors, was used to generate the 2D contribution maps in which red, white, and blue indicate positive, neutral, and negative contributions, respectively.

\subsection{Heat Maps}

Heat maps were constructed to delineate the physicochemical profile of 50 fragments that were highlighted as positive for biological activity. The positive fragments were identified using the 2D contributions maps and extracted from compounds that showed $\mathrm{pIC}_{50}>6$. The physicochemical properties were calculated using Canvas 2.9 (Schrodinger LLC, New York, NY, USA) [66] and used as inputs for the best $\mathrm{ANN}$, which then predicted the $\mathrm{pIC}_{50}$ for the fragment collection. Next, heat maps were built, in which the physicochemical properties that are associated with higher pIC $_{50}$ values could be visually assessed.

\section{Conclusions}

The discovery of novel drugs for Chagas' disease remains an outstanding challenge. Progress in this area requires the design of prototypes that combine activities against the molecular target and appropriate pharmacokinetics. Achieving a suitable balance among these different and occasionally conflicting properties requires the development of candidates with finely adjusted physicochemical properties. In this study, a set of 363 structurally diverse compounds covering a broad interval of trypanocidal activity was used to build highly predictive QSAR models. The final ANN showed high predictive power for test set compounds $\left(q^{2}=0.81\right)$ and identified critical physicochemical properties associated with the biological activity of the dataset. The best KPLS model, which yielded a $q^{2}$ value of 0.84 , highlighted key fragments strongly correlated with the anti-T. cruzi activity of the dataset compounds. The integration of the ANN and KPLS analyses enabled the generation of a privileged fragment collection, for which an optimal physicochemical space was determined. The structural information enclosed in the fragment collection along with the delineated physicochemical landscape are valuable information for guiding the design of novel antichagasic agents with improved properties.

Supplementary Materials: Supplementary material can be found at http:/www.mdpi.com/1422-0067/20/11/2801/ s1. 
Author Contributions: All authors contributed equally to this work. Formal analysis, A.S.d.O.; Investigation, A.S.d.S., L.L.G.F. and A.S.d.O.; Supervision, A.D.A.; Writing-original draft, A.S.d.S. and L.L.G.F.; Writing-review \& editing, A.D.A.

Funding: The authors acknowledge the National Council for Scientific and Technological Development (CNPq), the Coordination for the Improvement of Higher Education Personnel (CAPES), and the Sao Paulo Research Foundation (FAPESP, grant 2013/07600-3), Brazil, for financial support.

Conflicts of Interest: The authors declare no conflict of interest.

\section{Abbreviations}

$\begin{array}{ll}\text { ANN } & \text { Artificial Neural Network } \\ \text { KPLS } & \text { Kernel-based Partial Least Squares } \\ \text { IC }_{50} & \text { Concentration of compound that inhibits } 50 \% \text { of the growth of } T \text {. cruzi in phenotypic assays } \\ \text { pIC }_{50} & -\log \text { IC }_{50} \\ \text { QSAR } & \text { Quantitative Structure-Activity Relationships } \\ \text { WHO } & \text { World Health Organization } \\ \text { MW } & \text { Molecular Weight } \\ a \text { LogP } & \text { Octanol-Water Partition Coefficient } \\ \text { HBD } & \text { Hydrogen Bond Donors } \\ \text { HBA } & \text { Hydrogen Bond Acceptors } \\ \text { RB } & \text { Rotatable Bonds } \\ \text { PSA } & \text { Polar Surface Area } \\ \text { E-state } & \text { Electrotopological State } \\ \text { MR } & \text { Molar Refractivity } \\ \text { Polar } & \text { Molecular Polarizability } \\ \text { T. cruzi } & \text { Trypanosoma cruzi } \\ \text { RC } & \text { Ring Count } \\ \text { HAC } & \text { Heavy Atom Count }\end{array}$

\section{References}

1. Pérez-Molina, J.A.; Molina, I. Chagas disease. Lancet 2017, 6736, 82-94. [CrossRef]

2. World Health Organization. American Trypanosomiasis (Chagas disease). Available online: http://www. who.int/chagas/en/ (accessed on 10 February 2019).

3. Dias, J.C.; Ramos, A.N., Jr.; Gontijo, E.D.; Luquetti, A.; Shikanai-Yasuda, M.A.; Coura, J.R.; Torres, R.M.; Melo, J.R.; Almeida, E.A.; Oliveira, W., Jr.; et al. II Consenso Brasileiro em Doença de Chagas 2015. Epidemiol. Serv. Saude 2016, 25, 1-10. [CrossRef] [PubMed]

4. Kratz,J.M.; Bournissen, F.G.; Forsyth, C.J.; Sosa-Estani, S. Clinical and pharmacological profile of benznidazole for treatment of Chagas disease. Expert Rev. Clin. Pharmacol. 2018, 11, 943-957. [CrossRef] [PubMed]

5. Ferreira, L.L.G.; Andricopulo, A.D. Drugs and vaccines in the 21st century for neglected diseases. Lancet Infect. Dis. 2019, 19, 125-127. [CrossRef]

6. Tyler, K.M.; Engman, D.M. The life cycle of Trypanosoma cruzi. Int. J. Parasitol. 2001, 31, 472-481. [CrossRef]

7. Mandal, S. Epidemiological Aspects of Chagas Disease-A Review. J. Anc. Dis. Prev. Remedies 2014, 2, 1-7. [CrossRef]

8. Salto, M.L.; Bertello, L.E.; Vieira, M.; Docampo, R.; Moreno, S.N.J.; Lederkremer, R.M. De Formation and Remodeling of Inositolphosphoceramide during Differentiation of Trypanosoma cruzi from Trypomastigote to Amastigote. Eucaryotic Cell 2003, 2, 756-768. [CrossRef] [PubMed]

9. Lentini, G.; Pacheco, N.; dos, S.; Burleigh, B.A. Targeting host mitochondria: A role for the Trypanosoma cruzi amastigote flagellum. Cell. Microbiol. 2018, 20,1-8. [CrossRef]

10. Ferreira, L.G.; Oliva, G.; Andricopulo, A.D. From Medicinal Chemistry to Human Health: Current Approaches to Drug Discovery for Cancer and Neglected Tropical Diseases. An. Acad. Bras. Cienc. 2018, 90, 645-661. [CrossRef]

11. De Rycker, M.; Baragaña, B.; Duce, S.L.; Gilbert, I.H. Challenges and recent progress in drug discovery for tropical diseases. Nature 2018, 559, 498-506. [CrossRef]

12. Polinsky, A. Lead-Likeness and Drug-Likeness. Pract. Med. Chem. 2008, 244-254. [CrossRef] 
13. Gajdács, M. The Concept of an Ideal Antibiotic: Implications for Drug Design. Molecules 2019, $24,892$. [CrossRef] [PubMed]

14. Maltarollo, V.G.; Gertrudes, J.C.; Oliveira, P.R.; Honorio, K.M. Applying machine learning techniques for ADME-Tox prediction: A review. Expert Opin. Drug Metab. Toxicol. 2015, 11, 259-271. [CrossRef] [PubMed]

15. Singh, S. Preclinical Pharmacokinetics: An Approach Towards Safer and Efficacious Drugs. Curr. Drug Metab. 2006, 7, 165-182. [CrossRef] [PubMed]

16. Gajdács, M.; Handzlik, J.; Sanmartín, C.; Domínguez-Álvarez, E.; Spengler, G. Prediction of ADME properties for selenocompounds with anticancer and efflux pump inhibitory activity using preliminary computational methods. Acta Pharm. Hung. 2018, 88, 67-74.

17. Honorio, K.M.; Garratt, R.C.; Polikatpov, I.; Andricopulo, A.D. 3D QSAR comparative molecular field analysis on nonsteroidal farnesoid X receptor activators. J. Mol. Graph. Modell. 2007, 25, 921-927. [CrossRef] [PubMed]

18. Zhang, L.; Tan, J.; Han, D.; Zhu, H. From machine learning to deep learning: progress in machine intelligence for rational drug discovery. Drug Discov. Today 2017, 22, 1680-1685. [CrossRef] [PubMed]

19. Tian, S.; Wang, J.; Li, Y.; Li, D.; Xu, L.; Hou, T. The application of in silico drug-likeness predictions in pharmaceutical research. Adv. Drug Deliv. Rev. 2015, 86, 2-10. [CrossRef] [PubMed]

20. Schmidhuber, J. Deep Learning in neural networks: An overview. Neural Networks 2015, 61, 85-117. [CrossRef] [PubMed]

21. Lindgren, F.; Geladi, P.; Wold, S. Kernel-based PLS regression; Cross-validation and applications to spectral data. J. Chemom. 1994, 8, 377-389. [CrossRef]

22. Lecun, Y.; Bengio, Y.; Hinton, G. Deep learning. Nature 2015, 521, 436-444. [CrossRef] [PubMed]

23. Rumelhart, D.E.; Hinton, G.E.; Williams, R.J. Learning representations by back-propagating erros. Nature 1986, 323, 533-536. [CrossRef]

24. Cereto-Massagué, A.; Ojeda, M.J.; Valls, C.; Mulero, M.; Garcia-Vallvé, S.; Pujadas, G. Molecular fingerprint similarity search in virtual screening. Methods 2015, 71, 58-63. [CrossRef] [PubMed]

25. Duan, J.; Dixon, S.L.; Lowrie, J.F.; Sherman, W. Analysis and comparison of 2D fingerprints: Insights into database screening performance using eight fingerprint methods. J. Mol. Graph. Model. 2010, 29, 157-170. [CrossRef]

26. Gómez-Ayala, S.; Castrillón, J.A.; Palma, A.; Leal, S.M.; Escobar, P.; Bahsas, A. Synthesis, structural elucidation and in vitro antiparasitic activity against Trypanosoma cruzi and Leishmania chagasi parasites of novel tetrahydro-1-benzazepine derivatives. Bioorganic Med. Chem. 2010, 18, 4721-4739. [CrossRef]

27. King-Keller, S.; Li, M.; Smith, A.; Zheng, S.; Kaur, G.; Yang, X.; Wang, B.; Docampo, R. Chemical validation of phosphodiesterase $\mathrm{C}$ as a chemotherapeutic target in Trypanosoma cruzi, the etiological agent of Chagas' disease. Antimicrob. Agents Chemother. 2010, 54, 3738-3745. [CrossRef]

28. Magaraci, F.; Jimenez Jimenez, C.; Rodrigues, C.; Rodrigues, J.C.F.; Vianna Braga, M.; Yardley, V.; De Luca-Fradley, K.; Croft, S.L.; De Souza, W.; Ruiz-Perez, L.M.; et al. Azasterols as Inhibitors of Sterol 24-Methyltransferase in Leishmania Species and Trypanosoma cruzi. J. Med. Chem. 2003, 46, 4714-4727. [CrossRef]

29. Jones, S.M.; Urch, J.E.; Kaiser, M.; Brun, R.; Harwood, J.L.; Berry, C.; Gilbert, I.H. Analogues of thiolactomycin as potential antimalarial and anti-trypanosomal agents. J. Med. Chem. 2005, 48, 5932-5941. [CrossRef]

30. Zuccotto, F.; Brun, R.; Gonzalez, P.D.; Ruiz, P.L.M.; Gilbert, I.H. The structure-based design and synthesis of selective inhibitors of Trypanosoma cruzi dihydrofolate reductase. Bioorganic Med. Chem. Lett. 1999, 9, 1463-1468. [CrossRef]

31. Jonckers, T.H.M.; Van Miert, S.; Cimanga, K.; Bailly, C.; Colson, P.; De Pauw-Gillet, M.C.; Van den Heuvel, H.; Claeys, M.; Lemière, F.; Esmans, E.L.; et al. Synthesis, cytotoxicity, and antiplasmodial and antitrypanosomal activity of new neocryptolepine derivatives. J. Med. Chem. 2002, 45, 3497-3508. [CrossRef]

32. Szajnman, S.H.; Montalvetti, A.; Wang, Y.; Docampo, R.; Rodriguez, J.B. Bisphosphonates derived from fatty acids are potent inhibitors of Trypanosoma cruzi farnesyl pyrophosphate synthase. Bioorganic Med. Chem. Lett. 2003, 13, 3231-3235. [CrossRef]

33. Da Rosa, R.; de Moraes, M.H.; Zimmermann, L.A.; Schenkel, E.P.; Steindel, M.; Bernardes, L.S.C. Design and synthesis of a new series of 3,5-disubstituted isoxazoles active against Trypanosoma cruzi and Leishmania amazonensis. Eur. J. Med. Chem. 2017, 128, 25-35. [CrossRef] 
34. De Azeredo, C.M.O.; Ávila, E.P.; Pinheiro, D.L.J.; Amarante, G.W.; Soares, M.J. Biological activity of the azlactone derivative EPA-35 against Trypanosoma cruzi. FEMS Microbiol. Lett. 2017, 364, 1-7. [CrossRef]

35. Guerra, A.; Gonzalez-Naranjo, P.; Campillo, N.E.; Varela, J.; Lavaggi, M.L.; Merlino, A.; Cerecetto, H.; González, M.; Gomez-Barrio, A.; Escario, J.A.; et al. Novel Imidazo[4,5-c][1,2,6]thiadiazine 2,2-dioxides as antiproliferative Trypanosoma cruzi drugs: Computational screening from neural network, synthesis and in vivo biological properties. Eur. J. Med. Chem. 2017, 136, 223-234. [CrossRef]

36. Sykes, M.L.; Avery, V.M. Development and application of a sensitive, phenotypic, high-throughput image-based assay to identify compound activity against Trypanosoma cruzi amastigotes. Int. J. Parasitol. Drugs Drug Resist. 2015, 5, 215-228. [CrossRef]

37. De Menezes, D.; da, R.; Calvet, C.M.; Rodrigues, G.C.; de Souza Pereira, M.C.; Almeida, I.R.; de Aguiar, A.P.; Supuran, C.T.; Vermelho, A.B. Hydroxamic acid derivatives: A promising scaffold for rational compound optimization in Chagas disease. J. Enzyme Inhib. Med. Chem. 2016, 31, 964-973. [CrossRef]

38. Olmo, F.; Urbanová, K.; Rosales, M.J.; Martín-Escolano, R.; Sánchez-Moreno, M.; Marín, C. An in vitro iron superoxide dismutase inhibitor decreases the parasitemia levels of Trypanosoma cruzi in BALB/c mouse model during acute phase. Int. J. Parasitol. Drugs Drug Resist. 2015, 5, 110-116. [CrossRef]

39. Papadopoulou, M.V.; Bloomer, W.D.; Rosenzweig, H.S.; O'Shea, I.P.; Wilkinson, S.R.; Kaiser, M. 3-Nitrotriazole-based piperazides as potent antitrypanosomal agents. Eur. J. Med. Chem. 2015, 103, 325-334. [CrossRef]

40. Papadopoulou, M.V.; Bloomer, W.D.; Rosenzweig, H.S.; O'Shea, I.P.; Wilkinson, S.R.; Kaiser, M.; Chatelain, E.; Ioset, J.R. Discovery of potent nitrotriazole-based antitrypanosomal agents: In vitro and in vivo evaluation. Bioorganic Med. Chem. 2015, 23, 6467-6476. [CrossRef]

41. Neitz, R.J.; Bryant, C.; Chen, S.; Gut, J.; Hugo Caselli, E.; Ponce, S.; Chowdhury, S.; Xu, H.; Arkin, M.R.; Ellman, J.A.; et al. Tetrafluorophenoxymethyl ketone cruzain inhibitors with improved pharmacokinetic properties as therapeutic leads for Chagas' disease. Bioorganic Med. Chem. Lett. 2015, 25, 4834-4837. [CrossRef]

42. Sangenito, L.S.; d'Avila-Levy, C.M.; Branquinha, M.H.; Santos, A.L.S. Nelfinavir and lopinavir impair Trypanosoma cruzi trypomastigote infection in mammalian host cells and show anti-amastigote activity. Int. J. Antimicrob. Agents 2016, 48, 703-711. [CrossRef]

43. Santos, G.B.; Krogh, R.; Magalhaes, L.G.; Andricopulo, A.D.; Pupo, M.T.; Emery, F.S. Semisynthesis of new aphidicolin derivatives with high activity against Trypanosoma cruzi. Bioorganic Med. Chem. Lett. 2016, 26, 1205-1208. [CrossRef]

44. De Vita, D.; Moraca, F.; Zamperini, C.; Pandolfi, F.; Di Santo, R.; Matheeussen, A.; Maes, L.; Tortorella, S.; Scipione, L. In vitro screening of 2-(1H-imidazol-1-yl)-1-phenylethanol derivatives as antiprotozoal agents and docking studies on Trypanosoma cruzi CYP51. Eur. J. Med. Chem. 2016, 113, 28-33. [CrossRef]

45. Eberle, C.; Burkhard, J.A.; Stump, B.; Kaiser, M.; Brun, R.; Krauth-Siegel, R.L.; Diederich, F. Synthesis, inhibition potency, binding mode, and antiprotozoal activities of fluorescent inhibitors of trypanothione reductase based on mepacrine-conjugated diaryl sulfide scaffolds. ChemMedChem 2009, 4, 2034-2044. [CrossRef]

46. Palma, A.; Yépes, A.F.; Leal, S.M.; Coronado, C.A.; Escobar, P. Synthesis and in vitro activity of new tetrahydronaphtho[1,2-b]azepine derivatives against Trypanosoma cruzi and Leishmania chagasi parasites. Bioorganic Med. Chem. Lett. 2009, 19, 2360-2363. [CrossRef]

47. Herrera, C.; Vallejos, G.A.; Loaiza, R.; Zeledón, R.; Urbina, A.; Sepúlveda-Boza, S. In vitro activity of thienyl-2-nitropropene compounds against Trypanosoma cruzi. Mem. Inst. Oswaldo Cruz 2009, 104, 980-985. [CrossRef]

48. Rosso, V.S.; Szajnman, S.H.; Malayil, L.; Galizzi, M.; Moreno, S.N.J.; Docampo, R.; Rodriguez, J.B. Synthesis and biological evaluation of new 2-alkylaminoethyl-1,1- bisphosphonic acids against Trypanosoma cruzi and Toxoplasma gondii targeting farnesyl diphosphate synthase. Bioorganic Med. Chem. 2011, 19, 2211-2217. [CrossRef]

49. Eberle, C.; Lauber, B.S.; Fankhauser, D.; Kaiser, M.; Brun, R.; Krauth-Siegel, R.L.; Diederich, F. Improved Inhibitors of Trypanothione Reductase by Combination of Motifs: Synthesis, Inhibitory Potency, Binding Mode, and Antiprotozoal Activities. ChemMedChem 2011, 6, 292-301. [CrossRef] [PubMed] 
50. Sealey-Cardona, M.; Cammerer, S.; Jones, S.; Ruiz-Pérez, L.M.; Brun, R.; Gilbert, I.H.; Urbina, J.A.; González-Pacanowska, D. Kinetic characterization of squalene synthase from Trypanosoma cruzi: Selective inhibition by quinuclidine derivatives. Antimicrob. Agents Chemother. 2007, 51, 2123-2129. [CrossRef]

51. Franck, X.; Fournet, A.; Prina, E.; Mahieux, R.; Hocquemiller, R.; Figadère, B. Biological evaluation of substituted quinolines. Bioorganic Med. Chem. Lett. 2004, 14, 3635-3638. [CrossRef]

52. Khabnadideh, S.; Pez, D.; Musso, A.; Brun, R.; Ruiz Pérez, L.M.; González-Pacanowska, D.; Gilbert, I.H. Design, synthesis and evaluation of 2,4-diaminoquinazolines as inhibitors of trypanosomal and leishmanial dihydrofolate reductase. Bioorganic Med. Chem. 2005, 13, 2637-2649. [CrossRef] [PubMed]

53. Szajnman, S.H.; Ravaschino, E.L.; Docampo, R.; Rodriguez, J.B. Synthesis and biological evaluation of 1-amino-1,1-bisphosphonates derived from fatty acids against Trypanosoma cruzi targeting farnesyl pyrophosphate synthase. Bioorganic Med. Chem. Lett. 2005, 15, 4685-4690. [CrossRef] [PubMed]

54. Szajnman, S.H.; García Liñares, G.E.; Li, Z.H.; Jiang, C.; Galizzi, M.; Bontempi, E.J.; Ferella, M.; Moreno, S.N.J.; Docampo, R.; Rodriguez, J.B. Synthesis and biological evaluation of 2-alkylaminoethyl-1,1-bisphosphonic acids against Trypanosoma cruzi and Toxoplasma gondii targeting farnesyl diphosphate synthase. Bioorganic Med. Chem. 2008, 16, 3283-3290. [CrossRef] [PubMed]

55. Bringmann, G.; Brun, R.; Kaiser, M.; Neumann, S. Synthesis and antiprotozoal activities of simplified analogs of naphthylisoquinoline alkaloids. Eur. J. Med. Chem. 2008, 43, 32-42. [CrossRef] [PubMed]

56. Blanco, M.C.; Escobar, P.; Leal, S.M.; Bahsas, A.; Cobo, J.; Nogueras, M.; Palma, A. Synthesis of novel polysubstituted (2SR,4RS)-2-heteroaryltetrahydro-1,4- epoxy-1-benzazepines and cis-2-heteroaryl-4-hydroxytetrahydro-1H-1-benzazepines as antiparasitic agents. Eur. J. Med. Chem. 2014, 86, 291-309. [CrossRef] [PubMed]

57. Olmo, F.; Clares, M.P.; Marín, C.; González, J.; Inclán, M.; Soriano, C.; Urbanová, K.; Tejero, R.; Rosales, M.J.; Krauth-Siegel, R.L.; et al. Synthetic single and double aza-scorpiand macrocycles act as inhibitors of the antioxidant enzymes iron superoxide dismutase and trypanothione reductase in Trypanosoma cruzi with promising results in a murine model. RSC Adv. 2014, 4, 65108-65120. [CrossRef]

58. Braga, S.F.P.; Alves, É.V.P.; Ferreira, R.S.; Fradico, J.R.B.; Lage, P.S.; Duarte, M.C.; Ribeiro, T.G.; Júnior, P.A.S.; Romanha, A.J.; Tonini, M.L.; et al. Synthesis and evaluation of the antiparasitic activity of bis-(arylmethylidene) cycloalkanones. Eur. J. Med. Chem. 2014, 71, 282-289. [CrossRef] [PubMed]

59. Papadopoulou, M.V.; Bloomer, W.D.; Lepesheva, G.I.; Rosenzweig, H.S.; Kaiser, M.; Aguilera-Venegas, B.; Wilkinson, S.R.; Chatelain, E.; Ioset, J.R. Novel 3-nitrotriazole-based amides and carbinols as bifunctional antichagasic agents. J. Med. Chem. 2015, 58, 1307-1319. [CrossRef]

60. Keenan, M.; Alexander, P.W.; Diao, H.; Best, W.M.; Khong, A.; Kerfoot, M.; Thompson, R.C.A.; White, K.L.; Shackleford, D.M.; Ryan, E.; et al. Design, structure-activity relationship and in vivo efficacy of piperazine analogues of fenarimol as inhibitors of Trypanosoma cruzi. Bioorganic Med. Chem. 2013, 21, 1756-1763. [CrossRef]

61. Carvalho, S.A.; Feitosa, L.O.; Soares, M.; Costa, T.E.M.M.; Henriques, M.G.; Salomão, K.; De Castro, S.L.; Kaiser, M.; Brun, R.; Wardell, J.L.; et al. Design and synthesis of new (E)-cinnamic N-acylhydrazones as potent antitrypanosomal agents. Eur. J. Med. Chem. 2012, 54, 512-521. [CrossRef]

62. Galiana-Roselló, C.; Bilbao-Ramos, P.; Dea-Ayuela, M.A.; Rolón, M.; Vega, C.; Bolás-Fernández, F.; García-España, E.; Alfonso, J.; Coronel, C.; González-Rosende, M.E. In vitro and in vivo antileishmanial and trypanocidal studies of new N-benzene- and N-naphthalenesulfonamide derivatives. J. Med. Chem. 2013, 56, 8984-8998. [CrossRef] [PubMed]

63. Upadhayaya, R.S.; Dixit, S.S.; Földesi, A.; Chattopadhyaya, J. New antiprotozoal agents: Their synthesis and biological evaluations. Bioorganic Med. Chem. Lett. 2013, 23, 2750-2758. [CrossRef] [PubMed]

64. Silva-Júnior, E.F.; Silva, E.P.S.; França, P.H.B.; Silva, J.P.N.; Barreto, E.O.; Silva, E.B.; Ferreira, R.S.; Gatto, C.C.; Moreira, D.R.M.; Siqueira-Neto, J.L.; et al. Design, synthesis, molecular docking and biological evaluation of thiophen-2-iminothiazolidine derivatives for use against Trypanosoma cruzi. Bioorganic Med. Chem. 2016, 24, 4228-4240. [CrossRef] [PubMed]

65. Lipinski, C.A.; Lombardo, F.; Dominy, B.W.; Feeney, P.J. Experimental and computational approaches to estimate solubility and permeability in drug discovery and development settings. Adv. Drug Deliv. Rev. 1997, 23, 3-25. [CrossRef]

66. Canvas Schrödinger Release 2016-3. Available online: https://www.schrodinger.com/canvas (accessed on 9 January 2019). 
67. SYBYL-X. Available online: https://www.certara.com/pressreleases/certara-enhances-sybyl-x-drug-designand-discovery-software-suite/ (accessed on 9 January 2019).

68. Bender, A.; Mussa, H.Y.; Glen, R.C.; Reiling, S. Similarity searching of chemical databases using atom environment descriptors (MOLPRINT 2D): evaluation of performance. J. Chem. Inf. Comput. Sci. 2004, 44, 1708-1718. [CrossRef]

69. Hall, M.; Frank, E.; Holmes, G.; Pfahringer, B.; Reutemann, P.; Witten, I.H. The WEKA Data Mining Software: An Update. SIGKDD Explor. 2009, 11, 10-18. [CrossRef]

70. Cybenko, G. Approximation by Superpositions of a Sigmoidal Function. Math. Control. Signals Syst. 1989, 2, 303-314. [CrossRef]

71. An, Y.; Sherman, W.; Dixon, S.L. Kernel-based partial least squares: Application to fingerprint-based QSAR with model visualization. J. Chem. Inf. Model. 2013, 53, 2312-2321. [CrossRef]

(C) 2019 by the authors. Licensee MDPI, Basel, Switzerland. This article is an open access article distributed under the terms and conditions of the Creative Commons Attribution (CC BY) license (http://creativecommons.org/licenses/by/4.0/). 